\title{
NineTeen Complex-subunit Salsa is required for efficient splicing of a subset of introns and dorsal-ventral patterning
}

\author{
OM SINGH RATHORE, ${ }^{1}$ RUI D. SILVA, ${ }^{1}$ MARIANA ASCENSÃO-FERREIRA, ${ }^{2}$ RICARDO MATOS, ${ }^{1}$ \\ CÉLIA CARVALHO, ${ }^{2}$ BRUNO MARQUES, ${ }^{1}$ MARGARIDA N. TIAGO, ${ }^{1}$ PEDRO PRUDÊNCIO, ${ }^{1,2}$ \\ RAOUEL P. ANDRADE, ${ }^{1,3}$ JEAN-YVES ROIGNANT, ${ }^{4,5}$ NUNO L. BARBOSA-MORAIS, ${ }^{2}$ \\ and RUI GONÇALO MARTINHO ${ }^{1,2,6}$ \\ ${ }^{1}$ Center for Biomedical Research (CBMR), Universidade do Algarve, Faro, 8005-139 Portugal \\ ${ }^{2}$ Instituto de Medicina Molecular João Lobo Antunes, Faculdade de Medicina, Universidade de Lisboa, 1649-028 Lisboa, Portugal \\ ${ }^{3}$ Department of Medicine and Biomedical Sciences and Algarve Biomedical Center, Universidade do Algarve, 8005-139 Faro, Portugal \\ ${ }^{4}$ Center for Integrative Genomics, Faculty of Biology and Medicine, University of Lausanne, $\mathrm{CH}-1015$ Lausanne, Switzerland \\ ${ }^{5}$ Institute of Pharmaceutical and Biomedical Sciences, Johannes Gutenberg-University Mainz, 55128 Mainz, Germany \\ ${ }^{6}$ Department of Medical Sciences and Institute for Biomedicine (iBiMED), Universidade de Aveiro, 3810-193 Aveiro, Portugal
}

\begin{abstract}
The NineTeen Complex (NTC), also known as pre-mRNA-processing factor 19 (Prp19) complex, regulates distinct spliceosome conformational changes necessary for splicing. During Drosophila midblastula transition, splicing is particularly sensitive to mutations in NTC-subunit Fandango, which suggests differential requirements of NTC during development. We show that NTC-subunit Salsa, the Drosophila ortholog of human RNA helicase Aquarius, is rate-limiting for splicing of a subset of small first introns during oogenesis, including the first intron of gurken. Germline depletion of Salsa and splice site mutations within gurken first intron impair both adult female fertility and oocyte dorsal-ventral patterning, due to an abnormal expression of Gurken. Supporting causality, the fertility and dorsal-ventral patterning defects observed after Salsa depletion could be suppressed by the expression of a gurken construct without its first intron. Altogether, our results suggest that one of the key rate-limiting functions of Salsa during oogenesis is to ensure the correct expression and efficient splicing of the first intron of gurken mRNA. Retention of gurken first intron compromises the function of this gene most likely because it undermines the correct structure and function of the transcript $5^{\prime} U T R$.
\end{abstract}

Keywords: splicing; Drosophila; female fertility; dorsal-ventral patterning; Gurken

\section{INTRODUCTION}

The spliceosome is a highly dynamic molecular machine, composed of five small nuclear ribonucleoproteins (snRNPs) that sequentially associate to the precursor mRNA (pre-mRNA) during the splicing reaction (Martinho et al. 2015; Papasaikas and Valcarcel 2016). Each snRNP (U1, U2, U4, U5, and U6) contains a U-rich snRNA and a unique group of proteins. Although spliceosome assembly is ordered (U1>U2>U4/U5/U6 > NineTeen Complex), the splicing reaction is without an apparent irreversible and/or rate-limiting step (Hoskins et al. 2011), with commitment to splicing progressively increased as snRNPs and NTC bind to the pre-mRNA (Hoskins et al. 2011).

Corresponding authors: rgmartinho@ua.pt, nmorais@medicina. ulisboa.pt

Article is online at http://www.rnajournal.org/cgi/doi/10.1261/rna. 077446.120.
The spliceosomal NineTeen Complex (NTC), also known as Pre-mRNA-processing factor 19 (Prp19) complex, regulates distinct spliceosome conformational changes necessary for efficient pre-mRNA splicing (Hogg et al. 2010; Chanarat and Strasser 2013). NTC composition is dynamic and comprises a subset of conserved core subunits and many transiently associated ones (Hogg et al. 2010). NTC associates with the spliceosome during its activation and just before the first transesterification (Hogg et al. 2010). Interestingly, NTC also has a significant role in the crosstalk between transcription, cotranscriptional processing of the nascent RNA, and DNA repair, as distinct NTC subunits have been reported to be important for 
transcriptional elongation and genomic stability (Chanarat and Strasser 2013; Martinho et al. 2015; Mahajan 2016). Human NTC-subunits PRP19, XAB2, and CDC5L are important for transcriptional elongation, transcription-coupled DNA repair, and activation of the ATM-related (ATR)-dependent DNA damage checkpoint (Kuraoka et al. 2008; Marechal et al. 2014; Wan and Huang 2014). RNA Polymerase II (RNA Pol II) also promotes cotranscriptional splicing activation through the recruitment of NTC (David et al. 2011).

Human Aquarius (AQR) (also known as intron-binding protein 160, IBP160) is an ATP-dependent RNA helicase that associates with NTC during spliceosome activation and formation of the activated $B$ complex $\left(B^{A C T}\right.$ ) (Hirose et al. 2006; De et al. 2015; Haselbach et al. 2018). AQR binds to introns independently of sequence, but usually upstream of the branch-site (BS) and close to the associated U2 snRNP SF3a and SF3b proteins, being essential for intron-binding complex formation and efficient splicing (Hirose et al. 2006; De et al. 2015). AQR has also been suggested to be important for deposition of the exon junction complex (EJC) during the splicing reaction (Ideue et al. 2007) and formation of intron-encoded snoRNAs (Hirose et al. 2006), suggesting it regulates the cross-talk between splicing and other RNA processing events.

Splicing during Drosophila early embryonic development is notably sensitive to mutations in NTC-subunit Fandango (Guilgur et al. 2014), suggesting differential requirements of NTC during development (Martinho et al. 2015). To test this possibility, we decided to investigate the role of other NTC-subunits during Drosophila oogenesis and early embryonic development. We focused our initial work on uncharacterized gene CG31368, which encodes the Drosophila ortholog of human Aquarius (Herold et al. 2009; De et al. 2015). Since there is already a nonrelated Drosophila protease named aquarius (CG14061), we decided to rename CG31368 as salsa. Our working hypothesis is that salsa, similar to its Caenorhabditis elegans ortholog emb-4 (Akay et al. 2017), is likely to have important developmental functions.

During Drosophila oogenesis, gurken mRNA localizes to the posterior cortex of the developing oocyte and Gurken signal is restricted to the underlying posterior follicle cells (Schupbach 1987; Neuman-Silberberg and Schupbach 1993; Gonzalez-Reyes et al. 1995; Roth et al. 1995). In response to a signal from the posterior follicle cells, there is a considerable reorganization of the cytoskeleton and a microtubule-dependent migration of the oocyte nucleus to the anterior cortex (Gonzalez-Reyes and St Johnston 1994; Gonzalez-Reyes et al. 1995; Roth et al. 1995; Zhao et al. 2012). The anteriorly localized nucleus defines the dorsal-anterior region and provides the first detectable dorsal-ventral (D/N) asymmetry of the oocyte, with the expression of both gurken mRNA and protein restricted to the cytoplasmic perinuclear region of the oocyte
(Neuman-Silberberg and Schupbach 1993; GonzalezReyes et al. 1995; Roth et al. 1995).

gurken mRNA is transcribed in the supporting nurse cells (Caceres and Nilson 2005) and actively transported to the dorsal-anterior region of the oocyte by a dynein-mediated transport (MacDougall et al. 2003; Delanoue et al. 2007). The oocyte dorsal-anterior localization of gurken mRNA relies on multiple elements localized to the transcript 5'UTR, 3'UTR and open-reading frame (Saunders and Cohen 1999; Thio et al. 2000; Van De Bor et al. 2005). Although this localization is crucial for its efficient translation (Neuman-Silberberg and Schupbach 1993; Roth et al. 1995; Davidson et al. 2016), the precise contribution of each element for RNA localization is still a matter of debate.

D/N patterning of the developing Drosophila egg is dependent on the dorsal-anterior localization of Gurken during mid-oogenesis (Neuman-Silberberg and Schupbach 1993; Roth et al. 1995; Huynh and St Johnston 2004). Gurken is the ligand for the Epidermal growth factor receptor (Egfr) that locates to the apical surface of follicle cells that surround the developing oocyte (Schupbach 1987; Neuman-Silberberg and Schupbach 1993; GonzalezReyes et al. 1995; Roth et al. 1995). Activation of Egfr modifies the cell fate of the dorsal follicle cells and restricts the formation of Spätzle ligand to the ventral region of the oocyte (Morisato and Anderson 1994; Schneider et al. 1994), which is essential for normal morphogenesis of the eggshell dorsal appendages.

Here we found that Salsa, the Drosophila ortholog of $A Q R$, is rate-limiting for efficient splicing of a subset of small first introns, including the first intron of gurken. Consistent with the functional relevance of gurken splicing defects, mutations within the splice sites of the first intron of gurken impair the function of this gene. Female germline depletion of Salsa and splice mutations within gurken first intron were both associated to a decrease in female fertility, significant D/N patterning defects of the eggshell and abnormal expression of Gurken during oogenesis. Supporting causality, expression of a gurken construct without its first intron suppressed the female fertility and D/N patterning defects observed after Salsa depletion. Altogether our results suggest that one of the key rate-limiting functions of Salsa during oogenesis is to ensure the correct expression and efficient splicing of the first intron of gurken mRNA.

\section{RESULTS}

\section{Salsa is required for splicing of a subset of introns}

Splicing during Drosophila early embryonic development is particularly sensitive to mutations in NTC-subunit Fandango (Guilgur et al. 2014), suggesting differential requirements of NTC during development (Martinho et al. 
2015). To test this possibility, we decided to investigate the role of other NTC-subunits during Drosophila oogenesis and early embryonic development. We focused our initial work on the gene CG31368. Bidirectional blast analysis showed that CG31368 is the ortholog of human Aquarius (AQR) (Herold et al. 2009) (Flybase). CG31368 physically interacts with NTC-subunits Fandango and Prp19 (Guilgur et al. 2014), and this interaction is independent of RNA (Supplemental Fig. S1). Since there is already a nonrelated Drosophila protease named Aquarius, and given its interaction with Fandango, we decided to rename CG31368 as salsa.

In order to address the effect of Salsa on splicing we performed transcriptome analyses of control and Salsa-depleted ovaries. To deplete Salsa specifically within the female germline, the nanos-Gal4 (nos-Gal4) germline driver (Van Doren et al. 1998) and the upstream activating sequence (UAS)/Gal4 system (Brand and Perrimon 1993; Rorth 1998; Ni et al. 2011) were used to express short hairpin RNAs (shRNAs) against salsa. For control we used a short hairpin against mCherry. We focused our analysis on introns with good sequencing coverage and performed differential intron retention analysis between control and Salsa-depleted samples (for more experimental detail see Materials and Methods). A salsa RNAi hairpin (salsa RNAi-1) with a mild dorsal-ventral (D/N) patterning defect but without detectable egg chamber necrosis was used for this study in order to minimize the identification of introns whose splicing was nonspecifically affected by Salsa depletion.

Genome-wide analysis of the splicing defects observed after germline-specific depletion of Salsa showed that this RNA helicase is required for splicing of a small subset of introns, being the large majority of alternative splicing defects related to increased levels of intron retention (IR) upon Salsa depletion (Supplemental Fig. S2). Considering as biologically relevant a difference in percent of intron retention (PIR) of at least 10\% (see Materials and Methods), we identified a significant enrichment for increased intron retention, with 47 introns increasingly retained and only 6 introns less retained in Salsa-depleted samples (red/purple and yellow points in Fig. 1A; Supplemental Fig. S3A, respectively) (Supplemental Table S1). This proportion $(47 / 53 ; 0.89)$ is significantly different from 0.5 (proportion's test $P$-value $\left.=1.78 \times 10^{-8}\right)$. The fact that most identified cases were related with increased levels of intron retention is consistent with the recently proposed function of human Aquarius before splicing catalysis for increased pre-mRNA splicing efficiency (De et al. 2015).

Analysis of the introns that were more retained after Salsa depletion showed that this RNA helicase is required for efficient splicing, among others, of the first introns of the dorsal-ventral patterning gene gurken (Fig. 1B), the sex-determining gene transformer 2 (tra2) (Supplemental Fig. S3B), suppressor of variegation 205 (Su[var205), phos- phoribosylamidotransferase (Prat), CG18428 and multiprotein bridging factor 1 (mbf1), the second 5'UTRlocalized intron of CG7168, the fourth CG31211 intron, the third CG5746 intron and the fourth baboon (babo) intron (red points in Fig. 1A; Supplemental Fig. S3A; Supplemental Table S1).

\section{Salsa is required for splicing of small first introns}

Since gene architecture influences splicing kinetics (Sterner et al. 1996; Fox-Walsh et al. 2005; Pai et al. 2017) and given the fact that contrary to the first intron, splicing of the second and third introns of gurken was not affected by Salsa depletion (Fig. 1B), we decided to investigate if there was any particular feature significantly associated to introns whose splicing was sensitive to Salsa depletion. A comparison between differentially retained introns after Salsa depletion detected a significant bias for small proximal introns, as the affected introns had a higher probability of being first introns $(28 / 47 ; 0.6)$ compared to control $(62 / 169 ; 0.37$, proportion's test $P$-value $=0.0011)$ (Fig. 2A; Supplemental Fig. S4) or to commonly skipped introns $(636 / 4078 ; 0.16$, proportion's test $P$-value $<2.2 \times 10^{-16}$ ) (Fig. 2A; Supplemental Fig. S4), and were typically smaller than control introns (Wilcoxon's rank sum test with continuity correction $P$-value $=0.0046$ ) (Fig. 2B,C; Supplemental Fig. S5A).

Recruitment of $\mathrm{U} 1$ to the proximal region of nascent premRNAs is facilitated by interaction with the cap-binding complex (CBC) (Izaurralde et al. 1994; Lewis et al. 1996; Gornemann et al. 2005; Pabis et al. 2013), which protects against premature polyadenylation (Ashe et al. 1997; Gunderson et al. 1998; Guo et al. 2011) and facilitates splicing of $5^{\prime}$ end localized introns (Sakurai et al. 2002; Lin and Zhang 2005). The effect of CBC on splicing enhancement is distance dependent (Sakurai et al. 2002), with a significant positive correlation between transcription start site (TSS) distance and 5'splice site (5'ss) strength (Lepennetier and Catania 2016). Consistent with the hypothesis that Salsa is rate-limiting for CBC-dependent splicing, alternatively spliced introns with increased retention after Salsa depletion showed a bias for shorter distances between the transcription start site (TSS) and their 5'ss (average of 1060 base pairs) when compared to control introns (average of 3632 base pairs, Wilcoxon's $P$-value $=0.0014$ ) (Fig. 2D). Nevertheless, since this distance bias was not significant among first introns themselves (Fig. 2E; Supplemental Fig. S5B), suggesting it is mostly related with a first intron position bias and not the distance per se, and since there was no significant bias for weaker 5 'splice sites among the affected introns (Supplemental Fig. S6A), it is unlikely that the observed biases are related with CBC-dependent splicing. Interestingly, whereas affected introns showed a bias to weaker 3'splice sites when compared to control introns (Wilcoxon's P-value $=0.018$ ) (Fig. 2F,G; 


\section{Rathore et al.}

A

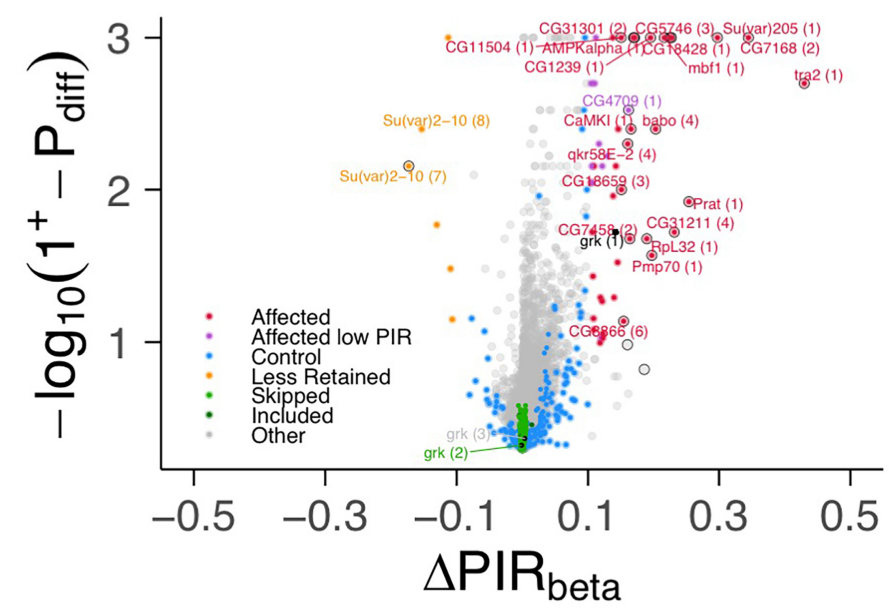

B

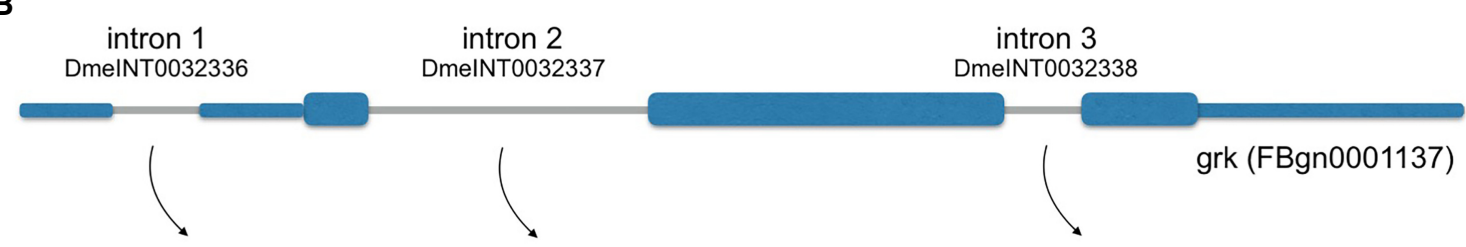

$\Delta P I R_{\text {beta }}=0.14, P_{\text {diff }}=0.98$

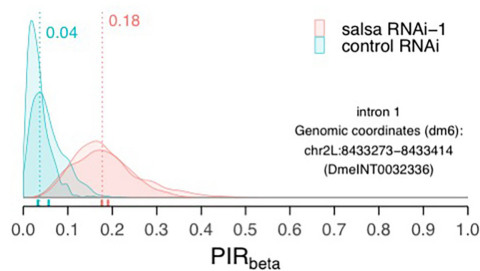

$\Delta \mathrm{PIR}$ beta $=0.00, \mathrm{P}_{\text {diff }}=0.50$

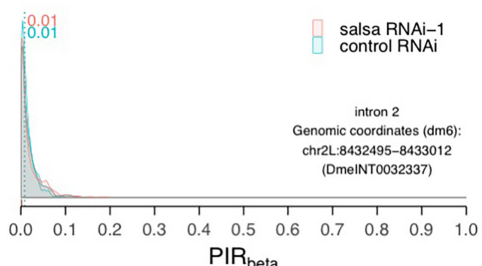

$\Delta \mathrm{PIR}_{\text {beta }}=0.00, \mathrm{P}_{\text {diff }}=0.59$

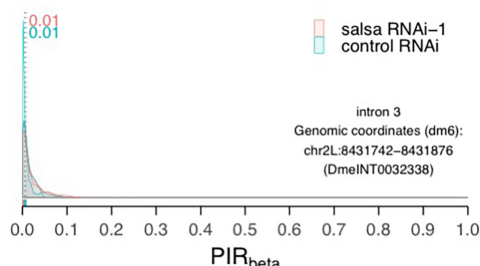

FIGURE 1. A subset of introns shows increased levels of retention (IR) upon Salsa depletion. (A) Volcano plot for beta distribution-based differential intron retention analysis, with differences in inclusion levels between Salsa-depleted (salsa RNAi-1) and control samples (mCherry RNAi) $\left(\Delta P I R_{\text {beta }}=P I R_{\text {salsa }} R N A i-P I R_{\text {control }}\right)$ in the $x$-axis and probability of differential retention $\left[-\log _{10}\left(1^{+}-P_{\text {diff }}\right)\right]$ in the $y$-axis, with $1^{+}=1.001$ used to avoid infinite values when $P_{\text {diff }}=1$. Differentially retained introns (Affected, Affected low $P I R$, and Less Retained), identified by $P_{\text {diff }} \geq 0.9$, are highlighted in red, purple and yellow, respectively. Events with an absolute $\Delta \mathrm{PIR}_{\text {beta }}$ greater than 0.15 are labeled with gene name and the transcript's intron position. Control, Included, and Skipped introns are also highlighted for comparison, as well as gurken intron retention events. Differential retention of the first intron of gurken is shown in black as this intron was filtered out of the global differential intron retention analysis due to insufficient coverage in one of the samples (see Materials and Methods). (B) Diagram of simplified gurken (grk) gene structure with exons (blue) and introns (gray) and density plots (smoothed histograms) reflecting points emitted from beta distributions used to model gurken intron 1 (left panel),

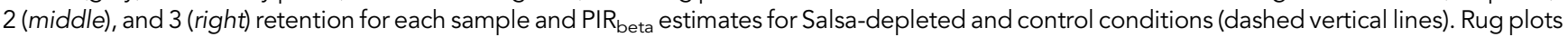
below the density curves reflect PIR values per sample. Event identifiers and genomic coordinates of the respective alternative sequences are part of the VAST-DB dm6 annotation (Tapial et al. 2017).

Supplemental Fig. S5C), there was, however, no bias for higher GC content (Supplemental Fig. S6B,C). Altogether our data suggests that Salsa is required for efficient splicing of first introns, typically smaller and with weaker 3 'splice sites, but independent of TSS distance.

\section{Salsa regulates the expression levels of a very small number of genes}

Human NTC-subunit Xab2, the ortholog of Drosophila Fandango (Guilgur et al. 2014), has been reported to be rate- limiting, besides splicing, for transcription and transcription-coupled repair (Kuraoka et al. 2008). Since Salsa physically interacts with Fandango (Guilgur et al. 2014), it was possible that transcription would be similarly affected in Salsa-depleted ovaries. Differential gene expression analysis revealed that Salsa is significantly rate-limiting for the expression levels of a very small number of genes (Supplemental Fig. S7A). Salsa positively regulates the expression levels of CG4570 and Activity-regulated cytoskeleton associated protein 1 (Arc1) (significantly down-regulated in Salsa-depleted ovaries) (Supplemental Fig. S7A; 
A

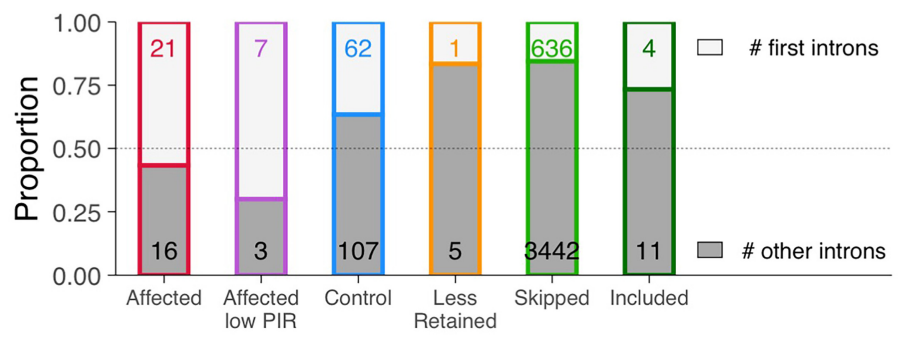

B

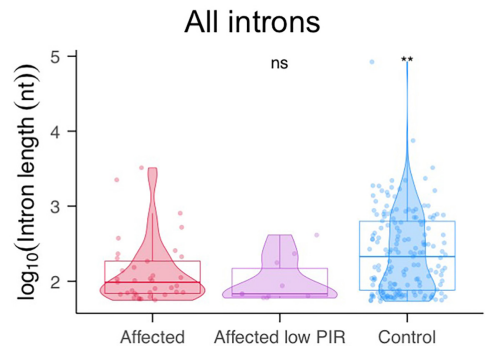

D

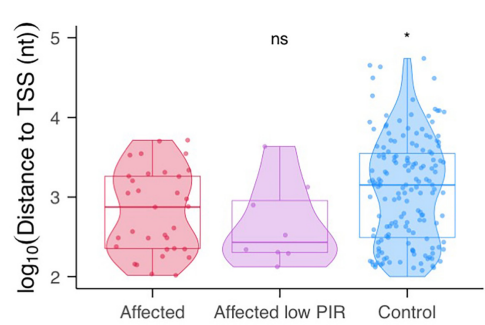

$\mathbf{F}$

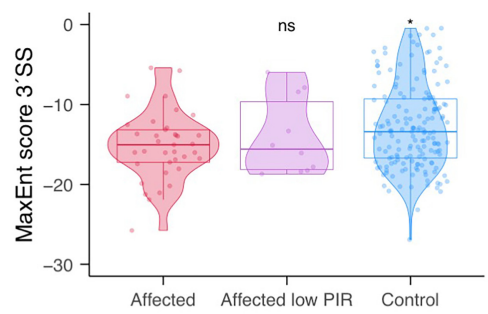

C

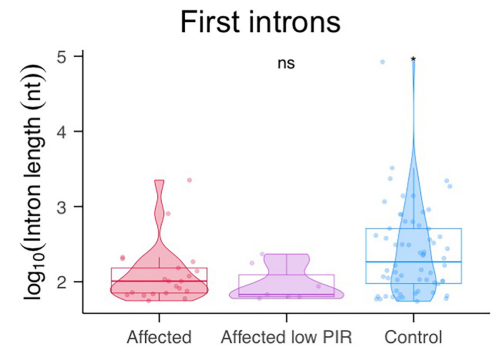

E

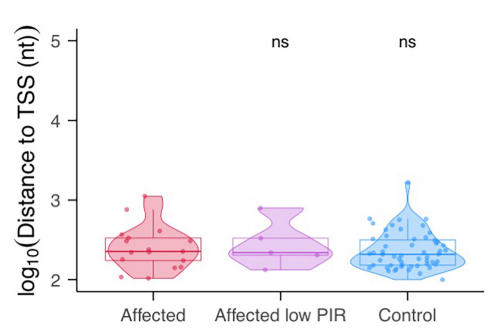

G

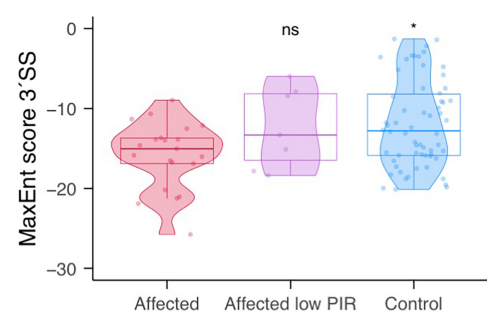

FIGURE 2. Small first introns show a bias for increased intron retention after Salsa depletion. (A) Proportion of first (white) and all other (gray) introns within each intron class, with the number of first introns/number of other introns indicated on top/bottom of each bar in color/black, respectively. (B-G) Violin plots and boxplots (highlighting the median, 25th and 75th percentiles per intron class) summarizing distributions of observations (each point refers to one intron) considering all introns (left panels) and first introns only (right panels) of: $(B, C) \log _{10}$ of intron length (nt); $(D, E) \log _{10}$ of distance (nt) between intron start and the transcript transcription start site (TSS); (F,G) Maximum entropy (MaxEnt) scores (Yeo and Burge 2004) for estimation of $3^{\prime}$ splice site efficiency, obtained with MATT (Gohr and Irimia 2019). Comparison of metrics in $B-G$ was performed with Affected as the reference: $\left({ }^{*}\right) P<0.05,\left({ }^{* *}\right) P<0.01$ and ns, nonsignificant (Wilcoxon rank-sum test with continuity correction).

Supplemental Table S2), whereas negatively regulates the expression of death resistor Adh domain containing target (Drat), Cyp4p2, sevenless (sev) and Insulin-like peptide 6 (Ilp6) (significantly up-regulated upon Salsa depletion) (Supplemental Fig. S7A; Supplemental Table S2). Significantly differentially expressed genes (B-statistic $>0$ ) are highlighted in red, while salsa (CG31368) is highlighted in black as a positive control (Supplemental Fig. S7A). Since there were no significant alterations in alternative splicing

of these genes (Supplemental Fig. S8), then these gene expression changes are more likely the result of a minor role of Salsa in transcription and/or an indirect consequence of the splicing defects observed after Salsa depletion. Nonsense-mediated decay pathway genes showed no differences in expression levels between conditions (blue points in Supplemental Fig. S7A-G), suggesting the decay pathway is similarly efficient in control and Salsa-depleted samples. Altogether these results suggest that Salsa is not rate-limiting for overall transcription and the observed splicing defects did not elicit a genomewide change of the transcriptome steady-state stability. This is consistent with previous results on fandango mutants where transcription was not obviously affected (Guilgur et al. 2014), and raises the possibility that contrary to human NTC, Drosophila NTC does not have any major role on transcription.

\section{Salsa is required for female fertility and eggshell dorsal- ventral patterning}

Since Salsa is required for efficient splicing of a subset of small first introns, including the first intron of gurken (Fig. 1B), we decided to investigate the function of this RNA helicase during oogenesis. To confirm that the observed RNAi phenotypes were due to Salsa depletion, and not a consequence of an off-target effect of the used salsa RNAi construct, three nonoverlapping shRNAs were used against salsa (salsa RNAi-1, salsa RNAi-2, and salsa RNAi-3). Since germline expression of salsa RNAi-3 was associated to significant levels of egg chamber necrosis, salsa RNAi-1 and salsa RNAi-2 constructs were mostly used in this manuscript to avoid nonspecific phenotypes. Depletion of Salsa within the female germline resulted in a strong reduction of salsa mRNA levels in the ovaries and unfertilized eggs/embryos (Fig. 3A; Supplemental Fig. S9A). Depletion of salsa mRNA was stronger in unfertilized eggs/embryos (maternal contribution) than in the ovaries (Supplemental Fig. S9A). This is most likely because Salsa is expressed in 
A

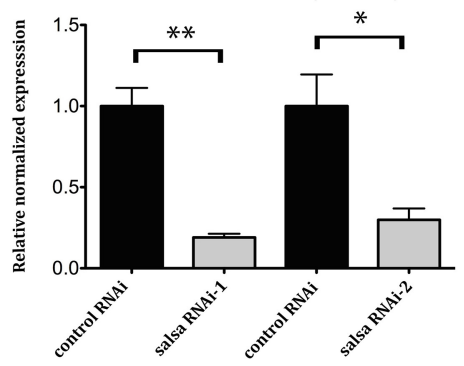

C Eggshell dorsal appendages defects

control RNAi

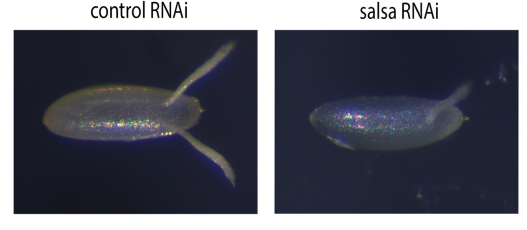

B

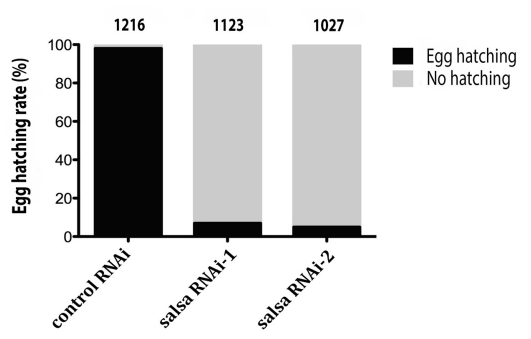

D Quantification of eggshell phenotypes

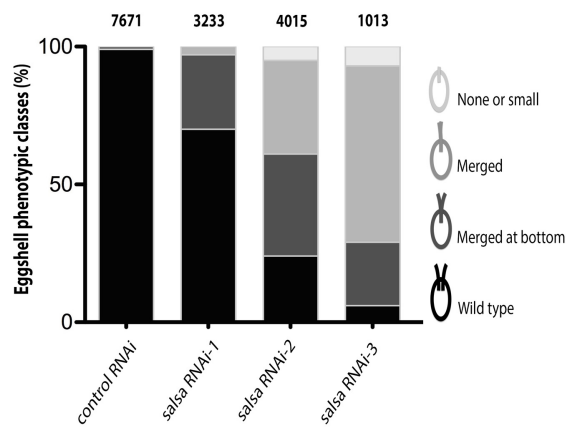

FIGURE 3. Salsa is required for female fertility and eggshell dorsal-ventral patterning. (A) Efficient depletion of salsa mRNA after germline-specific RNAi (nanos-Gal4 and UAS-salsa RNAi). RT-qPCR analysis of salsa mRNA in control (mCherry RNAi) and Salsa-depleted ovaries (two nonoverlapping shRNAs: salsa RNAi-1 and salsa RNAi-2). Relative normalized expression corresponds to values normalized with two distinct reference genes ( $\beta$-actin and GAPDH) and relative to negative control ( $m$ Cherry RNAi). At least three biological replicates were used for all shown results. Error bars indicate standard deviation. (B) Female fertility (egg hatching) was significantly reduced after germline-specific depletion of Salsa. Virgin females were crossed with wild-type males, and female fertility was calculated by the frequency of egg hatching $48 \mathrm{~h}$ post oviposition. Number of eggs scored for each experiment are indicated above the bar plot. (C, D) Germline-specific depletion of Salsa (three nonoverlapping shRNAs: salsa RNAi-1, salsa RNAi-2, and salsa RNAi-3) impaired eggshell dorsal-ventral patterning. (C) A significant proportion of the eggs laid by females whose germline was depleted for Salsa showed ventralized eggshells, with highly abnormal (fused or partially fused) dorsal appendages (D) Quantification of eggshell dorsal appendages defects (eggshell ventralization). Observed phenotypes were categorized in four different phenotypic classes based on the eggshell dorsal appendages: class 0: wild-type dorsal appendages-two individualized dorsal appendages); class 1: dorsal appendages only fused at bottom; class 2: fused dorsal appendages-spindle phenotype; and class 3: short eggs (dumpless-like phenotype) without or with extremely short dorsal appendages. Number of eggs scored for each experiment are indicated above the bar plot. Examples of scored phenotypes are shown in Supplemental Figure S10.

the soma (modEncode project; Graveley et al. 2011) and the dissected ovaries contain supporting somatic cells not affected by the germline-specific RNAi depletion. We next tested the effect of depleting Salsa in adult female fertility and observed that, after being mated with wild-type males, there was a strong reduction in egg hatching (Fig. 3B).

The reduced fertility of Salsa-depleted females was most likely related to the observed eggshell dorsal appendages defects (Fig. 3C,D), as this is suggestive of dorsal-ventral (D/N) patterning defects (Neuman-Silberberg and Schupbach 1993, 1994). For phenotypic quantifica- tion, we grouped the observed eggshell dorsal appendages phenotypes in four different classes: class 0 : wild-type dorsal appendages, class 1: dorsal appendages only fused at bottom, class 2: fused dorsal appendages (spindle phenotype), and class 3: short eggs (dumpless-like phenotype) without or with extremely short dorsal appendages. Examples of scored phenotypes are shown in Supplemental Figure S10. Eggs laid by control females (mCherry RNAi) showed wild-type dorsal appendages, suggestive of normal D/N patterning of the oocyte, whereas a significant proportion of the eggs laid by females whose germline was depleted for Salsa showed ventralized eggshells, with highly abnormal (fused or partially fused) dorsal appendages (Fig. 3C,D; for more experimental detail see Materials and Methods). The ventralized eggshell phenotypes were observed for all three salsa RNAi constructs. Suggesting that the dorsal-ventral patterning defects observed with salsa RNAi-1 and salsa RNAi-2 hairpins are hypomorphic phenotypes, the ventralized phenotype of salsa RNA-3 hairpin was more severe. In addition, there were significant levels of egg chamber necrosis with salsa RNAi-3 and after germline mutant clones of salsa (using the publicly available transposon allele PBac\{RB\}CG31368 ${ }^{\mathrm{e00215}}$ ). Altogether these results show that Salsa is required within the germline for female fertility, possibly because it is important for $D / V$ patterning of the developing oocyte. The dumpless-like phenotype also suggests residual levels of nurse cells dumping defects (Ferreira et al. 2014).

\section{Salsa is required for splicing of the first intron of gurken mRNA}

The gurken gene encodes a single transcript with three introns (Neuman-Silberberg and Schupbach 1993), with the first intron localized to the gene $5^{\prime}$ UTR, and the second and third introns localized to the gene open-reading frame. Since Salsa-depleted eggshell phenotypes were reminiscent of the ones observed in hypomorphic alleles 
of gurken (Schupbach 1987), and since our RNA-seq results suggested that Salsa is required for efficient splicing of the first intron of gurken (Fig. 1B), we hypothesized that salsa D/V patterning phenotypes were due to defects of gurken expression.

To confirm the gurken splicing defects, we performed reverse transcription-quantitative PCR (RT-qPCR) to quantify the relative levels of intron retention after Salsa depletion. Specific primers flanking the 3'splice site of all three introns of gurken were designed so that signal amplification would only occur in the presence of the intron (for used primer sequence see Supplemental Table S3). Consistent with our previous results, after depletion of Salsa there was a significant increase in the retention of the first intron, but not of the second and third introns, of gurken mRNA (Fig. 4A). To accurately determine gurken first intron unspliced/spliced ratio, we performed reverse transcriptase droplet digital PCR (RT-ddPCR). Specific primers and probe sets for unspliced or spliced first intron gurken transcripts were designed (for used primers and probes sequence see Supplemental Table S3). Interestingly, whereas in control ovaries (mCherry RNAi) the first intron of gurken unspliced/ spliced ratio was only $0.06 \pm 0.0072$ (Fig. 4B,C), after Salsa depletion (salsa RNAi-2), this ratio increased to $0.33 \pm$ 0.015 (Fig. 4B,C). Altogether, these results show that $\mathrm{Salsa}$ is required for efficient splicing of the first intron of gurken.

\section{Salsa is required for dorsal- anterior localization of gurken mRNA}

The correct dorsal-anterior localization of gurken mRNA has been reported to rely on multiple elements localized to the transcript $5^{\prime}$ UTR, $3^{\prime} U T R$ and open-reading frame (Saunders and Cohen 1999; Thio et al. 2000; Van De Bor et al. 2005). Since the 5'UTR of gurken mRNA was suggested to be necessary for its correct dorsal-anterior localization (Saunders and Cohen 1999; Thio et al. 2000), and Salsa depletion was associated with retention of the 5'UTR-localized first intron, we hy-

A pothesized that Salsa was required for dorsal-anterior localization of gurken mRNA.

To test this hypothesis, we performed fluorescence in situ hybridization with antisense RNA probes against gurken mRNA. For phenotypic quantification, we grouped the observed gurken mRNA localization phenotypes in three different classes: (i) normal localization, (ii) partial localization, and (iii) no localization. Examples of scored phenotypes are shown in Supplemental Figure S11 (for more experimental detail see Materials and
RT-qPCR: analysis of gurken mRNA splicing
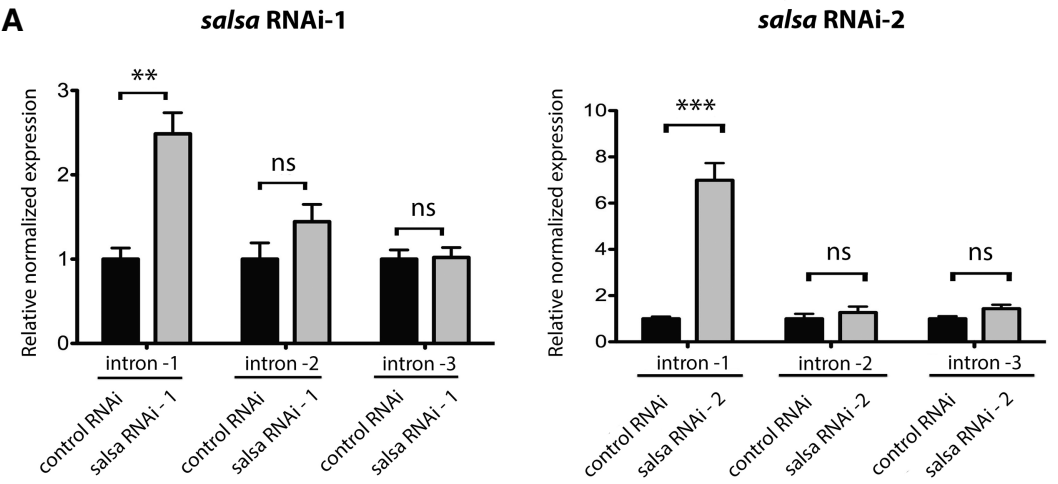

RT-ddPCR: analysis of gurken mRNA splicing (1st intron)
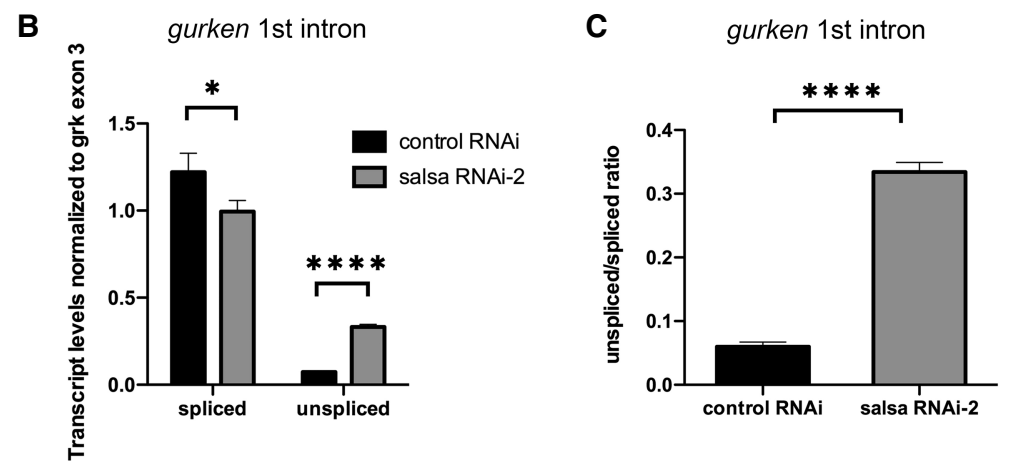

FIGURE 4. Salsa is required for splicing of the first intron of gurken mRNA. Germline-specific depletion of Salsa is associated with a significant increase in the retention of the first intron, but not of the second and third introns, of gurken mRNA. (A) RT-qPCR analysis of gurken transcript using intron-exon primers and an iScript cDNA library (random hexamer and oligo [dT] reaction mix). Germline-specific depletion of Salsa induced a significant retention of the first intron of gurken transcript, whereas the second and third introns were correctly spliced. Shown are the fold changes of intron retention. Relative normalized expression corresponds to values normalized with two distinct reference genes ( $\beta$-actin and GAPDH) and relative to control conditions (mCherry RNAi). At least three biological replicates were used for each data set. Error bars indicate standard deviation. $(B, C)$ Reverse transcription droplet digital PCR (RT-ddPCR) of gurken to accurately determine first intron unspliced/spliced ratio. Whereas in control ovaries (mCherry RNAi) the unspliced/spliced ratio of the first intron of gurken was only $0.06 \pm 0.0072$, after Salsa depletion (salsa RNAi-2) it raised to $0.33 \pm 0.015$. (B) Accurate quantification, by ddPCR, of spliced and unspliced isoforms of gurken first intron, relative to reference sequence: After Salsa depletion, there was an enrichment in unspliced intron 1 (unspliced t-test, $P<$ 0.00001 ) and the corresponding decrease in intron 1 removal by splicing (spliced t-test, $P=$ 0.011). (C) Graphic representation of the increase in gurken first intron ratio unspliced/spliced after Salsa depletion (salsa RNAi-2) ( $t$-test, $P<0.00001)$. Two biological replicates were used for each RT-ddPCR data set. Error bars indicate standard deviation. 
Methods). Consistent with the observed eggshell dorsal appendages defects, depletion of Salsa was associated with a reduction of the dorsal-anterior localization of gurken mRNA. Whereas egg chambers from control females (mCherry RNAi) showed a normal dorsal-anterior localization of gurken mRNA during mid-oogenesis (Fig. $5 A, B)$, a significant proportion of egg chambers from fe- males whose germline were depleted for Salsa showed a detectable reduction of dorsal-anterior localized gurken mRNA (Fig. 5A,B). Interestingly, the reduction of localized gurken transcript was proportional to the severity of eggshell ventralization and gurken mRNA splicing defects (compare salsa RNAi-1 and RNAi-2 in Figs. 3D, $4 A, 5 A, B)$.
A Fluorescence in situ hybridization of gurken mRNA

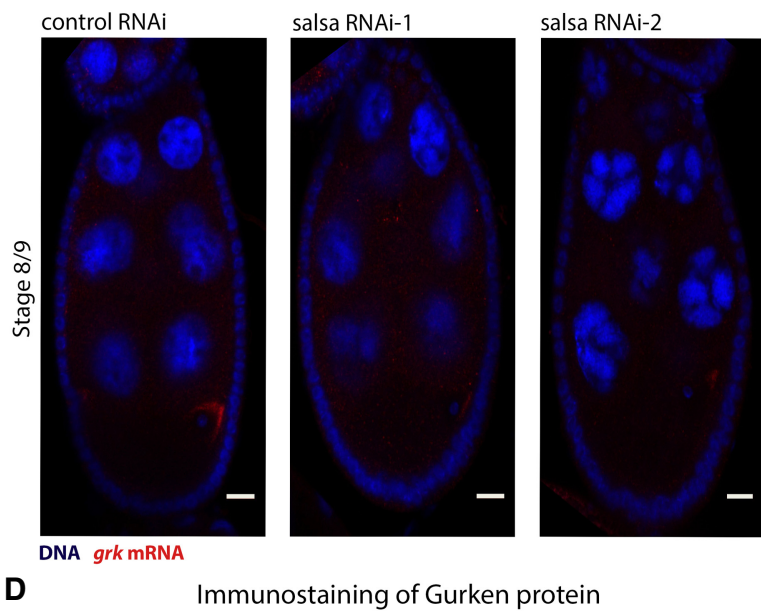

D

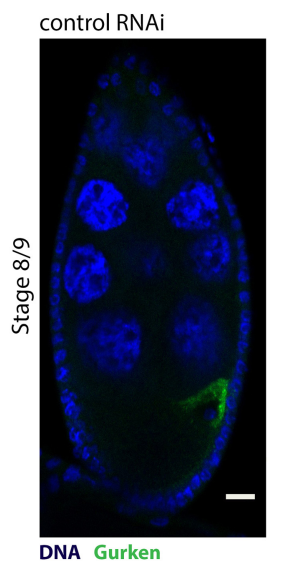
salsa RNAi-1

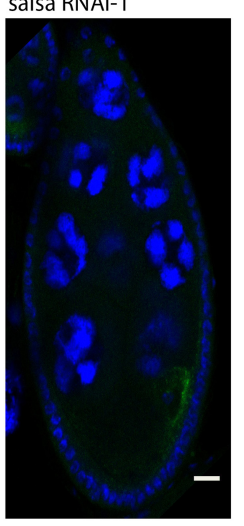

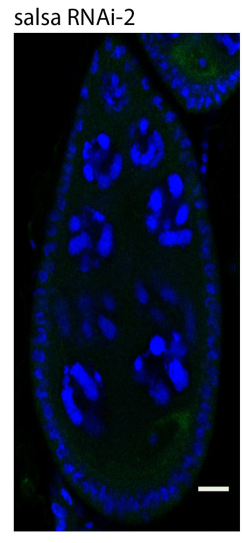

B

Quantification of gurken mRNA localization

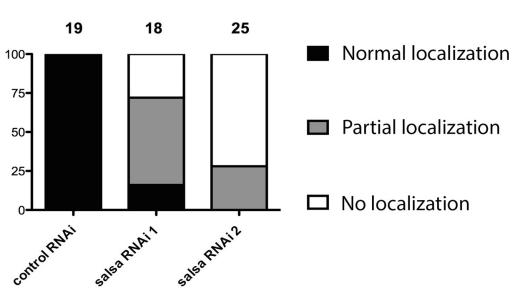

C

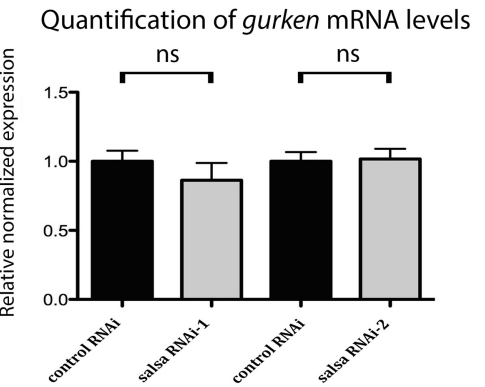

E

Quantification of Gurken protein levels

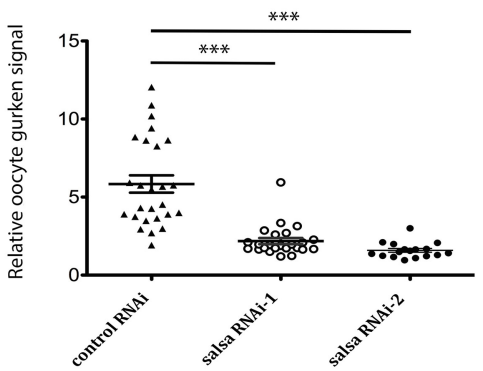

FIGURE 5. Salsa is required for dorsal-anterior expression of Gurken. $(A, B)$ Salsa is required for oocyte dorsal-anterior localization of gurken mRNA. (A) Germline-specific depletion of Salsa impaired dorsal-anterior localization of gurken mRNA during mid-oogenesis. Fragmented digoxigenin-labeled antisense RNA probes were used to detect gurken mRNA in situ. Visualization of probes was done using an anti-Digoxigenin Cy3 secondary antibody. DNA (blue) and gurken mRNA (red). Scale bar, $10 \mu \mathrm{m}$. (B) Quantification of anterior dorsal localization defects of gurken mRNA in stage 8/9 egg chambers using three phenotypic classes: "normal localization," "partial localization," and "no localization." Additional examples of scored phenotypes are shown in Supplemental Figure S11. Negative control (mCherry RNAi): 100\% "normal DV localization" ( $n=19$ ); Salsa depletion (salsa RNAi-1): 16\% "normal DV localization," 56\% "partial DV localization," and 28\% "no DV localization" ( $n=$ 18); Salsa depletion (salsa RNAi-2): 0\% "normal DV localization," $28 \%$ "partial DV localization," and $72 \%$ shows "no DV localization" ( $n=25)$. (C) Salsa is not required for stability of gurken mRNA. Real-time GPCR analysis detected no significant reduction of total levels gurken mRNA after depletion of Salsa. Relative normalized expression corresponds to values normalized with two distinct reference genes ( $\beta$-actin and GAPDH) and relative to negative control (mCherry RNAi). At least three biological replicates were used for all data sets. Error bars indicate standard deviation. $(D, E)$ Salsa is required for oocyte dorsal-anterior localization of Gurken. (D) Immunostaining of Gurken during mid-oogenesis (stage 8/9 egg chambers). Gurken was detected with an anti-Gurken monoclonal antibody and DNA was visualized with DAPI staining. DNA (Blue) and Gurken (green). Scale bar $10 \mu \mathrm{m}$. (E) Relative oocyte Gurken dorsal anterior signal (arbitrary units [a.u.]) corresponds to Gurken signal pixel intensity (average of three different measurements taken from the oocyte dorsal-anterior region with the highest perinuclear signal) divided by the respective background signal (average of three different measurements from the respective nurse cells cytoplasm). To minimize sample variation, all measurements were obtained from maximum intensity projections obtained from confocal $Z$ stacks of stage $8 / 9$ egg chambers. Each dot represents an individual stage 8/9-egg chamber. Horizontal lines specify mean values and asterisks indicate significant difference (two-tailed unpaired t-test; $P<0.001$ ). 
Since abnormally processed mRNAs are usually targeted for degradation (Popp and Maquat 2013), we next tested if the steady-state stability of gurken mRNA was reduced after salsa depletion, as this would easily explain the reduced levels of localized gurken transcript. Using RTGPCR, we failed to detect any significant reduction in the total levels of gurken mRNA in the ovaries after depletion of Salsa (Fig. 5C; Supplemental Fig. S9B). Consistently, gurken was also not found to be differentially expressed in Salsa-depleted samples when compared to control $(\log F C=-0.64$, and B-statistics $=-4.36)$ in our RNA-seq experiment. Suggesting that Salsa depletion does not prevent nuclear export of gurken mRNA from the nurse cells, significant levels of intron retention could be detected within the maternally loaded gurken mRNAs from mature oocytes/early embryos (Supplemental Fig. S9C).

\section{Salsa is required for dorsal-anterior localization of Gurken protein}

Since dorsal-anterior localization of gurken mRNA was reduced after depletion of Salsa (Fig. 5A,B), we hypothesized that a similar reduction was likely to occur for Gurken protein. To test this hypothesis, we performed an immunostaining of Gurken using an anti-Gurken antibody (Queenan et al. 1999) in Drosophila egg chambers. Gurken accumulated at high levels in the cytoplasmic perinuclear dorsal-anterior region of control oocytes (mCherry RNAi) (Fig. 5D), whereas such expression was significantly reduced after depletion of Salsa (Fig. 5D,E; see Materials and Methods for Gurken levels quantification). Since we failed to detect the total levels of Gurken protein in the ovaries by western blot, using the currently available antibodies, it is unclear if this reduction results from reduced levels of protein translation and/or mislocalization. Altogether, our results show that Salsa is required for normal dorsal-anterior expression of Gurken, most likely because it is rate limiting for efficient splicing of the first intron of gurken transcript.

\section{Retention of the first intron of gurken impairs Gurken expression and function}

If Salsa is rate limiting for dorsal-anterior expression of Gurken because it is required for efficient splicing of the first intron of gurken, then mutations within its $5^{\prime}$ and $3^{\prime}$ splice sites should similarly impair the function and expression of this gene. To examine such a possibility, we investigated if a genomic construct of gurken with its own endogenous promoter but with or without splice site mutations within the transcript's first intron (for more experimental detail see Materials and Methods) could complement two amorphic/loss-of-function alleles of gurken. grk ${ }^{\text {deltaFRT }}$ is an amorphic deletion allele of gurken (Lan et al. 2010), whereas grk ${ }^{H F}$ contains a premature stop codon that severely truncates Gurken protein (Thio et al.
2000). Females homozygous for grk ${ }^{\text {deltaFRT }}$ or transheterozygous for grk $^{\text {deltaFRT} / g r k ~}{ }^{H F}$ are viable but sterile (Thio et al. 2000; Lan et al. 2010), as mutant egg chambers and eggshells show severe antero-posterior and dorsoventral patterning defects (Thio et al. 2000; Lan et al. 2010) and egg laying is severely compromised (Lan et al. 2010).

Supporting the hypothesis that splicing of the first intron of gurken is important for the expression and function of this gene, a wild-type genomic construct of gurken $\left(g k^{W T}\right)$, but not an identical construct carrying first intron splice site mutations ( $g r^{\text {splice site mutant) }}$ (splice site mutation: GT/AG to TT), could efficiently rescue the female sterility, eggshell dorsal appendages defects, and abnormal Gurken expression of gurken mutant females (Fig. 6A,B, $D, E)$. It should be noticed that a proportion of the L1 larvae

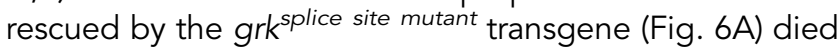
after hatching. Interestingly, and although these mutations completely abrogated splicing of the first intron of gurken (Fig. 6G), there was no detectable reduction of the expression levels of gurken transcript (Fig. 6F).

\section{Deletion of the first intron of gurken does not impair Gurken expression and function}

Splicing has been previously reported to be important for transcript localization. For example, the first intron of oskar is required for posterior localization of oskar mRNA, as its splicing recruits the exon junction complex (EJC) and generates a short RNA stem-loop structure both important for kinesin 1-dependent transport to the posterior (Hachet and Ephrussi 2004; Ghosh et al. 2012). In order to investigate if splicing of the first intron of gurken is per se important for gurken mRNA localization and function, we decided to test if a genomic construct of gurken with its own endogenous promoter but without the first intron could complement two amorphic/ loss-of-function alleles of gurken. Deletion of the first intron of gurken did not impair gurken expression levels (Supplemental Fig. S12). Since both wildtype and first intron-deleted genomic constructs (respectively, grk ${ }^{W T}$ and grk ${ }^{\text {no }} 1$ st intron) could similarly rescue fertility (Fig. 6A) and eggshell dorsal appendages (Fig. 6B,C) of gurken mutant females, we concluded that, contrary to oskar, deletion of the first intron of gurken does not impair the expression and function of this gene. Altogether these results suggest that splicing of the first intron of gurken is important for the expression and function of this gene, not because splicing is per se rate-limiting for transcript localization, but because retention of the first intron is likely to disturb the structure of the $5^{\prime}$ UTR of gurken mRNA.

\section{Deletion of the first intron of gurken rescues the D/V patterning defects after Salsa depletion}

Our results show that Salsa is rate-limiting for efficient splicing of the first intron of gurken and its depletion is 
associated with significant defects in Gurken dorsal-anterior expression. Since the 5'UTR of gurken mRNA was reported to be required for mRNA localization (Saunders and Cohen 1999; Thio et al. 2000), gurken first intron localizes to the transcript 5'UTR and its retention impairs the function of this gene (Fig. 6A,B), we reasoned that expression of a genomic construct of gurken lacking its first

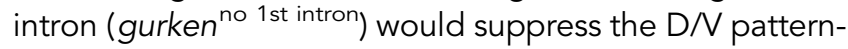
ing defects after Salsa depletion. Consistently, expression of a genomic construct of gurken lacking its first intron

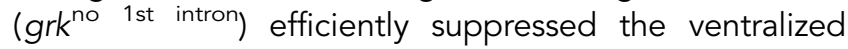
eggshell phenotypes observed after depletion of Salsa

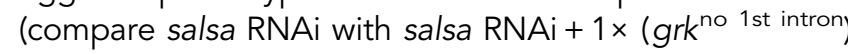
in Fig. 7A). Since expression of a wild-type genomic con- struct of gurken ( grk $^{\mathrm{WT}}$ ) also suppressed, albeit less efficiently, the eggshell defects after Salsa depletion (compare salsa RNAi with salsa RNAi + 1× $\left(g k^{\mathrm{WT}}\right)$ in Fig. 7A), it is still possible that Salsa regulates Gurken dorsal-anterior expression by additional mechanisms beyond splicing of gurken first intron. Significantly, the egg hatching defects after salsa depletion could be partially suppressed by the expression of a genomic construct of gurken lacking its first intron (gurken no first intron), but not by the expression of a wild-type gurken construct (Fig. 7B). This suggests that although depletion of Salsa impairs efficient splicing of multiple introns, gurken mRNA is one of the key rate-limiting transcripts regulated by this RNA helicase during oogenesis. Altogether our results strongly suggest that the
A

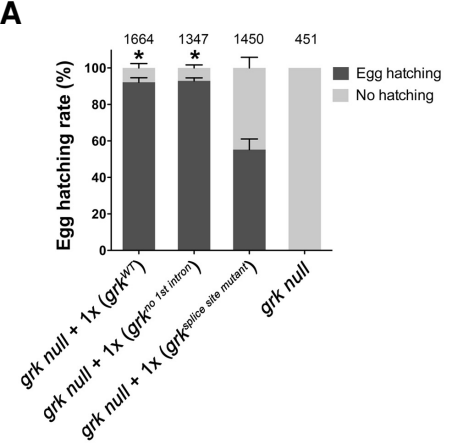

B

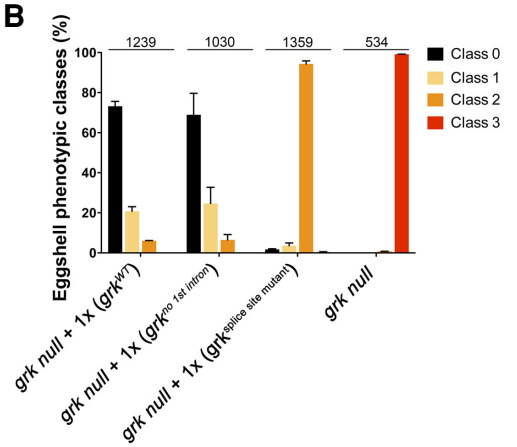

C

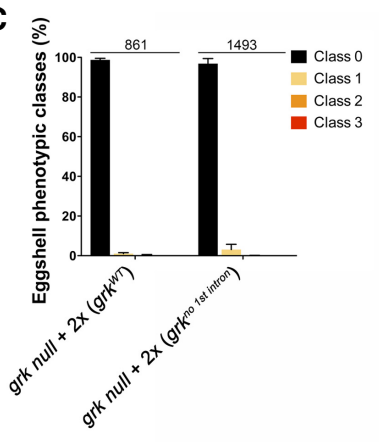

D

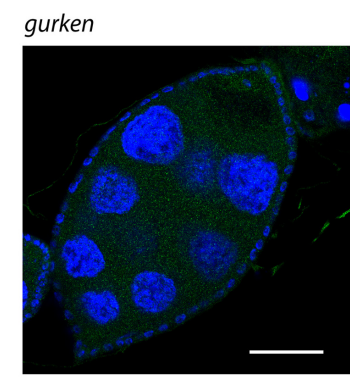

gurken + 1x (grkWT)

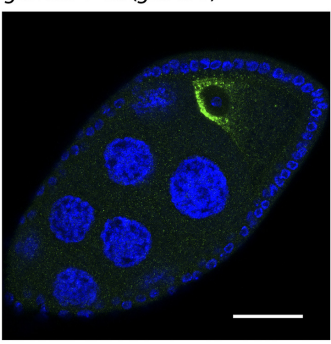

gurken $+1 \times(g r k W T)$

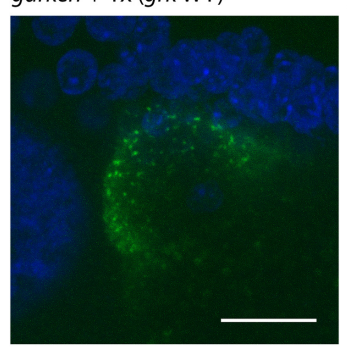

DNA Gurken

E

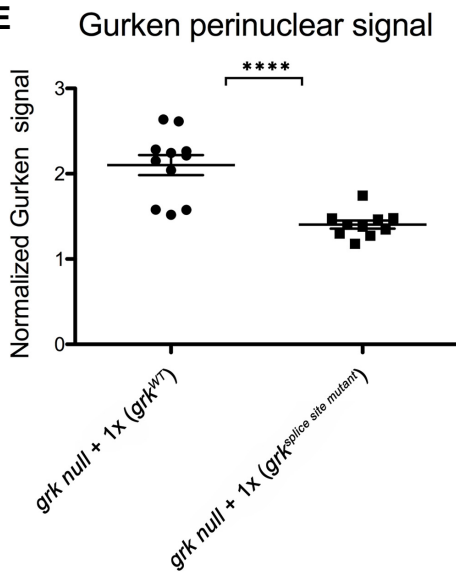

F gurken transcript levels

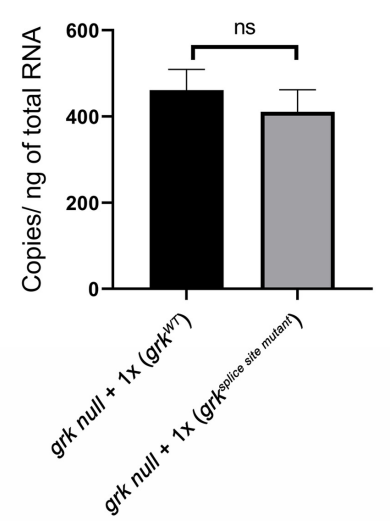

G

gurken 1st intron

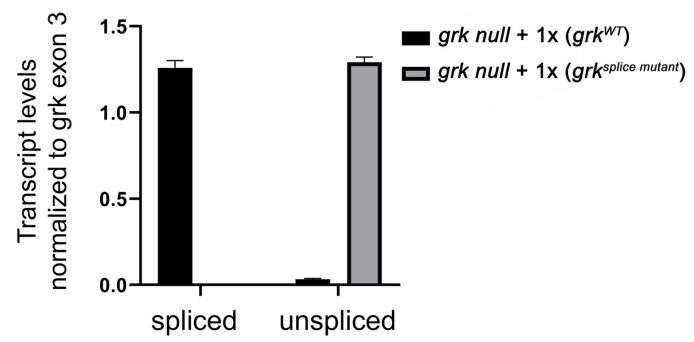

FIGURE 6. (See legend on next page)

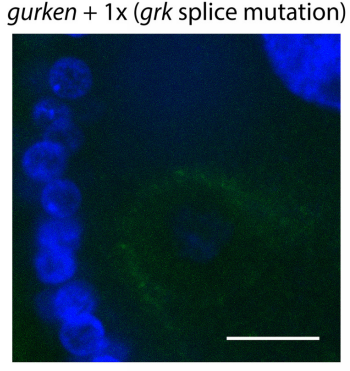

Splice site mutation: GT/AG to TT 
female fertility and D/V eggshell patterning defects observed after Salsa-depletion are mostly due to defects of Gurken expression and splicing.

\section{Salsa is required for eggshell dorsalization after increased gurken dosage}

D/N patterning is sensitive to gurken dosage (NeumanSilberberg and Schupbach 1994). Consistently, expression of a genomic construct containing wild-type gurken ( $g r k^{\mathrm{WT}}$ ), in an otherwise wild-type genetic background (three copies of gurken: two endogenous and one corresponding to the genomic transgene), induced significant eggshell dorsalization defects (Fig. 7C; dorsalization corresponds to class -2 and -1 ), whereas 2 copies of grk $^{W T}$ fully rescued the $\mathrm{D} / \mathrm{V}$ patterning defects of a loss-of-function allele of gurken (compare Figs. 6C, 7C). Depletion of Salsa partially suppressed the dorsalization phenotype after three copies of gurken (compare wild-type genomic construct of gurken $\left[\mathrm{grk}^{\mathrm{WT}}\right]$ in Fig. 7A,C), further confirming the requirement of Salsa for dorsal-anterior expression of Gurken during oogenesis.

\section{D/V patterning defects after Salsa depletion are not due to a persistent activation of the meiotic checkpoint}

Accumulation of persistent DNA damage during oogenesis leads to meiotic checkpoint activation, which severely disrupts oocyte nucleus morphology (Abdu et al. 2002; Klattenhoff et al. 2007) and embryonic anterior-posterior and dorsal-ventral axis specification by inhibiting the function of Vasa (Ghabrial and Schupbach 1999; Klattenhoff et al. 2007). Vasa is a DEAD box RNA helicase required for efficient translation of gurken (Styhler et al. 1998).

Although depletion of Salsa impairs dorsal-anterior expression of gurken and D/V patterning of the eggshell is severely compromised, the microtubule-dependent migration of the posterior oocyte nucleus to the anterior cortex was mostly unaffected (Fig. 5; Supplemental Fig. S11). Furthermore, and contrary to the highly abnormal oocyte nucleus observed after the accumulation of persistent DNA damage (Abdu et al. 2002), we failed to detect any oocyte nuclear abnormalities after Salsa depletion (Supplemental Fig. S13), suggesting that the observed

FIGURE 6. Splicing of the first intron of gurken is required for Gurken expression and function. Females homozygous for grk ${ }^{\text {deltaFRT }}$ are viable but sterile, with egg laying severely compromised (Lan et al. 2010). grk deltaFRT corresponds to an amorphic allele of gurken (deletion mutant) (Lan et al. 2010), whereas grk $\mathrm{HF}^{\mathrm{HF}}$ contains a single base pair change that introduces a precocious stop codon that severely truncates Gurken protein (Thio et al. 2000). (A) Expression of one copy of a genomic construct of gurken with its own endogenous promoter, with (grk ${ }^{\mathrm{WT}}$ ) or without ( grk $^{\text {no } 1 \text { st intron }) ~ t h e ~ t r a n s c r i p t ~ f i r s t ~ i n t r o n, ~ r e s c u e d ~ f e r t i l i t y ~(e g g ~ h a t c h i n g) ~ o f ~ g r k ~ n u l l ~(g r k ~}{ }^{\text {deltaFRT }} / g r k^{H F}$ ) females. Expression of one copy of a genomic

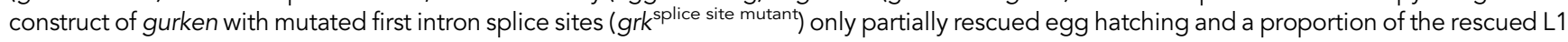
larvae died after eclosion. Number of eggs scored for each experiment are indicated above the bar plot and are the sum of two independent experiments. $t$-test analysis shows that expression of $g \mathrm{k}^{\mathrm{WT}}(P=0.0144)$ or grk $^{\text {no }}$ 1st intron $(P=0.0128)$ significantly increased egg hatching rate when compared to the expression of grk ${ }^{\text {splice site mutant }}$. (B) Expression of one copy of a genomic construct of gurken with its own endogenous promoter, with $\left(g r k^{\mathrm{WT}}\right)$ or without ( $g r k^{\mathrm{no}} 1$ st intron) the transcript first intron, rescued eggshell dorsal appendages defects (eggshell ventralization)

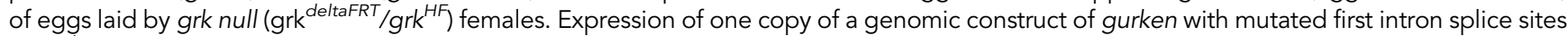
( grk $^{\text {splice site mutant) }}$ only weakly rescued eggshell ventralization. Number of eggs scored for each experiment are indicated above the bar plot and are the sum of two independent experiments. (C) Expression of two copies of a genomic construct of gurken with its own endogenous promoter, with ( $g r k^{\mathrm{WT}}$ ) or without ( $\left.g r k^{\text {no } 1 s t ~ i n t r o n}\right)$ the transcript first intron, fully rescued eggshell dorsal appendages defects (eggshell ventralization) of eggs

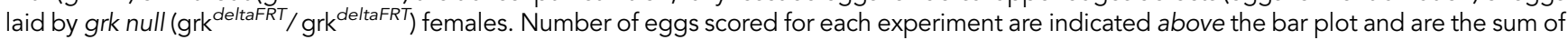
two independent experiments. $(B, C)$ For quantification of eggshell dorsal appendages defects (eggshell ventralization), observed phenotypes were categorized in four different phenotypic classes based on the eggshell dorsal appendages: class 0: wild-type dorsal appendages-two individualized dorsal appendages); class 1: dorsal appendages only fused at bottom; class 2: fused dorsal appendages—spindle phenotype; and class 3: short eggs (dumpless-like phenotype) without or with extremely short dorsal appendages. Examples of scored phenotypes are shown in Supplemental Figure S10. $(D, E)$ Eggs from grk null ( grk $^{\text {deltaFRT }} / g^{H}{ }^{H F}$ ) females lack detectable Gurken protein. Expression of one copy of a wildtype genomic construct of gurken ( r $^{\mathrm{WT}}{ }^{\mathrm{T}}$ ) rescued dorsal anterior expression of Gurken. Retention of the first intron due to splice site mutations ( grk $^{\text {splice site mutant) }}$ significantly decreased Gurken dorsal anterior expression. First intron 5' and $3^{\prime}$ splice sites (respectively, GT and AG) were both mutated to TT. Gurken was detected with an anti-Gurken monoclonal antibody and DNA was visualized with DAPI staining. DNA (Blue) and Gurken (green). Scale bars, 30 and $15 \mu \mathrm{m}$ (respectively, first two and last two images). (E) Relative oocyte Gurken dorsal anterior signal (arbitrary units [a.u.]) corresponds to Gurken signal pixel intensity (average of three different measurements taken from the oocyte dorsal-anterior region with the highest perinuclear signal) divided by the respective background signal (average of three different measurements from the respective oocyte cytoplasm). To minimize sample variation all measurements were obtained from maximum intensity projections obtained from confocal $Z$ stacks of stage 8/9/10 egg chambers. Each dot represents an individual egg chamber. Horizontal lines specify mean values and asterisks indicate significant difference (two-tailed unpaired $t$-test; $P<0.0001$ ). ( $F$ ) Expression of a genomic construct of gurken, without or with first intron splice site

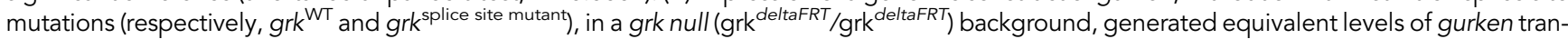
scripts. Respectively, RT-ddPCR (see Materials and Methods) measured 460.9 \pm 48.6 and $410.6 \pm 51$ copies of gurken mRNA (exon3) per ng of

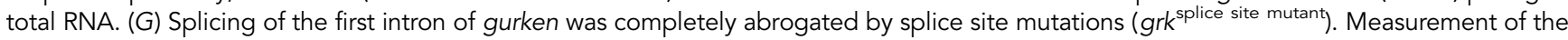
gurken first intron spliced and unspliced isoforms relative to exon 3. Splice site mutant shows total retention, while in wild-type it was only a $0.03 \pm 0.006$ for unspliced ratio. Wild-type constructs show $1.26 \pm 0.044$ for first intron spliced transcripts, whereas the splice site mutant shows $1.29 \pm 0.031$ for unspliced transcripts. The percentage of unspliced first intron was calculated as the ratio unspliced/(spliced + unspliced). For $\mathrm{grk}^{\mathrm{WT}}$, the unspliced ratio is $2.5 \pm 0.41 \%$, whereas $\mathrm{grk}^{\text {splice site mutant }}$ completely abrogates first intron splicing $\left(\mathrm{grk}^{\text {splice site }}\right.$ mutant $=100 \pm$ $0.002 \%)$. At least two biological replicates were done for each experiment. Error bars indicate standard deviation. 

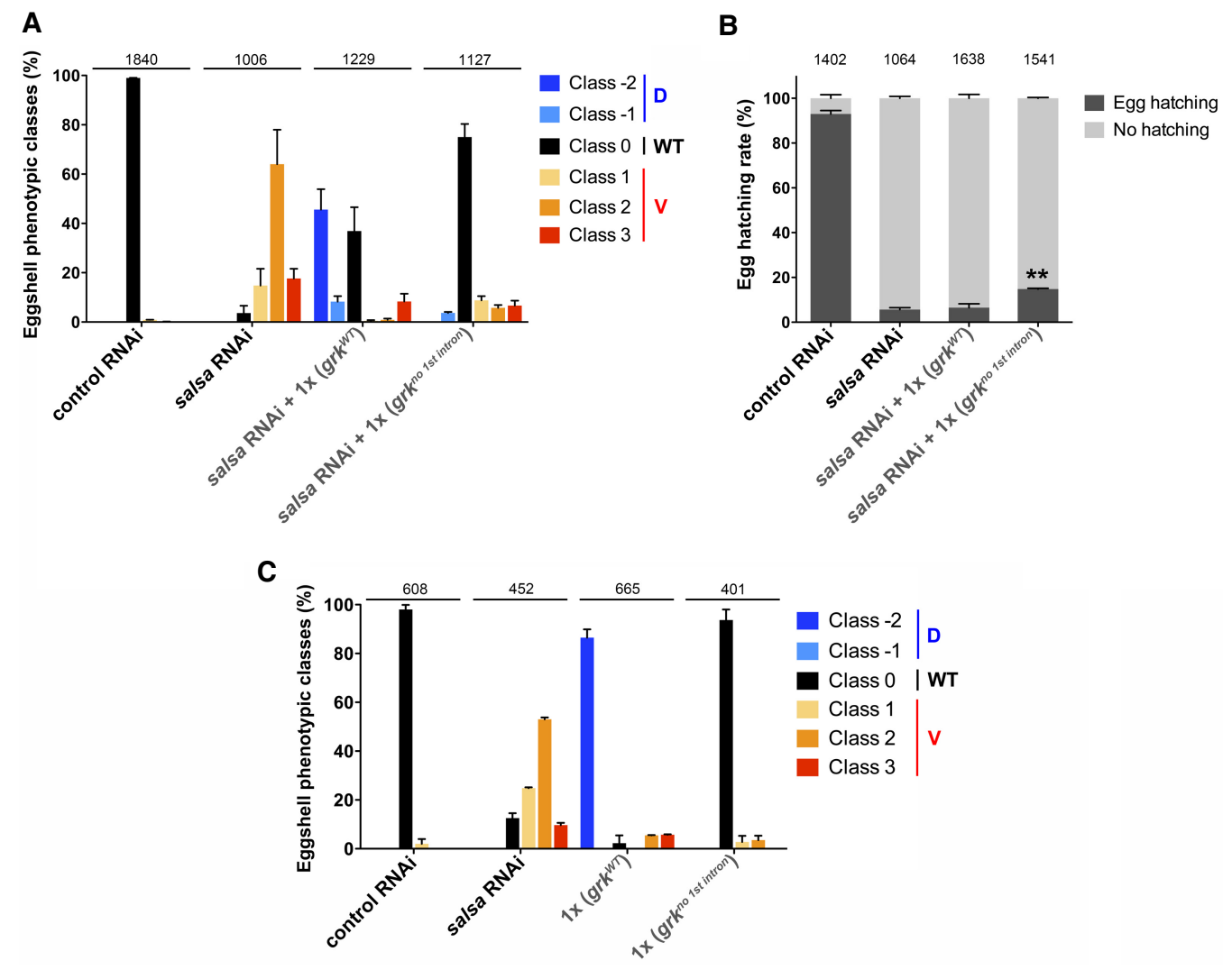

FIGURE 7. Deletion of the first intron of gurken rescues the D/V patterning defects of Salsa depletion. (A) Eggs laid by control females ( $\mathrm{mCherry}$ RNAi) showed wild-type dorsal appendages (WT), whereas a significant proportion of the eggs laid by females whose germline was depleted for Salsa (nanos-Gal4 and salsa RNAi-2) showed eggshell ventralization ( $($ ), with highly abnormal (fused or partially fused) dorsal appendages (classes 1 and 2). Expression of a genomic construct of gurken with its own endogenous promoter, with ( grk $^{\mathrm{WT}}$ ) or without the transcript first intron ( grk $^{\text {no } 1 \text { st intron }}$ ), suppressed the eggshell ventralization defects of eggs laid by females whose germline was depleted for Salsa (salsa RNAi-2). Suppression of $g k^{\text {no }} 1$ st intron was significantly better than $g \mathrm{Kk}^{\mathrm{WT}}$, with a higher frequency of wild-type eggshells (class 0 ). Number of eggs scored for each experiment is indicated above the bar plot and is the sum of two independent experiments. (B) Control females (mCherry RNAi) are fertile (egg hatching), whereas a significant proportion of the eggs laid by females whose germline was depleted for Salsa (nanos-Gal4 and salsa RNAi-2) did not hatch. While expression of one copy of a genomic construct of wild-type gurken ( $\mathrm{grk}^{\mathrm{WT}}$ ) did not rescue fertility, expression of one copy of a similar genomic construct of gurken without the transcript first intron ( $g r k^{\text {no }}$ 1st intron) partially rescued the fertility defects after Salsa depletion (salsa RNAi-2), (**) $P=0.0053$; t-test analysis. Number of eggs scored for each experiment are indicated above the bar plot and are the sum of two independent experiments. (C) Expression of a genomic construct of gurken ( $\mathrm{grk}^{\mathrm{WT}}$ ) in an otherwise wild-type genetic background (1x $\mathrm{grk}^{\mathrm{WT}}$; three copies of gurken: two endogenous and one corresponding to the genomic transgene) induced a significant eggshell dorsalization (D) (classes -2 and -1). Eggshell dorsalization was not observed after expression of a genomic construct of gurken without the first intron of gurken mRNA (1 $\times$ grk $^{\text {no }}$ 1st intron $)$. Number of eggs scored for each experiment is indicated above the bar plot and is the sum of two independent experiments. For quantification of eggshell dorsal appendages defects, the observed phenotypes were categorized in six different phenotypic classes based on the eggshell dorsal appendages. Class 0 corresponds to wild-type eggshell dorsal appendages (WT). Eggshell ventralization (V) of the eggshells corresponds to classes 1 to 3 . Eggshell dorsalization (D) corresponds to classes -1 and -2 . Class 0 (wild-type dorsal appendages): two individualized dorsal appendages); class 1: dorsal appendages only fused at bottom; class 2: fused dorsal appendages-spindle phenotype; and class 3: short eggs (dumpless-like phenotype) without or with extremely short dorsal appendages. Class -1: corresponds to short eggs with dorsalized appendages; class -2: corresponds to a broad and thick crown of appendage material or a broad/fused appendage that covers the entire width of the eggshell. Examples of scored phenotypes are shown in Supplemental Figure S10.

D/N patterning phenotypes are not mediated by persistent activation of the meiotic checkpoint.

\section{Salsa is required for nurse cells chromosome dispersal}

During early oogenesis, the nurse cell chromosomes undergo several rounds of endoreplication that results in a characteristic polytene blob-like appearance (Dej and Spradling 1999). This chromatin architecture disappears by stage $5 / 6$ with the dispersal of the nurse cells polytene chromosomes. Besides the previously described D/V patterning defects (eggshell dorsalization), mutants for squid (sqd), hrb27C, and half pint (hfp) also show defects in nurse cells chromosome dispersal (Van Buskirk and Schupbach 2002; Goodrich et al. 2004), clearly suggesting that these 
proteins regulate multiple processes during oogenesis. Interestingly, whereas alternative splicing of ovarian tumor (otu) was abnormal in sqd and hfp mutants, ectopic expression of the $104 \mathrm{kDa}$ Otu isoform was sufficient to rescue the nurse cells chromosome dispersal phenotype of these mutants (Van Buskirk and Schupbach 2002; Goodrich et al. 2004).

Ovaries depleted for Salsa showed nurse cells chromosome dispersal defects (Fig. 5D) identical to the ones previously observed in sqd and hfp mutants (Van Buskirk and Schupbach 2002; Goodrich et al. 2004). Nonetheless, Salsa is most likely not functionally related with Sqd and $\mathrm{Hfp}$, as Salsa depletion is associated with eggshell ventralization, and not dorsalization, and it did not significantly impair alternative splicing of otu (Supplemental Fig. S14).

Our results suggest that although the female fertility defects after Salsa depletion are clearly related to an abnormal splicing and expression of gurken, other phenotypes, like the nurse cells chromosome dispersal defects may also give a contribution for such reduction of female fertility.

\section{DISCUSSION}

\section{Salsa regulates expression and efficient splicing of gurken}

Oocyte dorsal-anterior localization of gurken mRNA relies on multiple elements localized to the transcript $5^{\prime} U T R$, $3^{\prime}$ UTR and open-reading frame (Saunders and Cohen 1999; Thio et al. 2000; Van De Bor et al. 2005), yet the relative importance of each element for mRNA localization is still unclear. The $5^{\prime}$ and $3^{\prime}$-UTRs of gurken were reported to be required for dorsal-anterior localization of gurken transcript (Saunders and Cohen 1999). Furthermore, and using a genomic gurken construct with a lacZ reporter inserted within the gene open-reading frame, it was shown that whereas gurken $5^{\prime}$ UTR is required for transcript oocyte accumulation, its coding region and $3^{\prime}$ UTR are necessary for its posterior and dorsal-anterior localization (Thio et al. 2000). Nevertheless, it was recently reported, using an oocyte injection assay, that a small stem-loop located within the open-reading frame was necessary and sufficient for gurken transcript localization (Van De Bor et al. 2005).

Our results show that efficient splicing of the first intron of gurken is required for mRNA dorsal-anterior localization and dorsal-ventral patterning. This is most likely because retention of the first intron impairs the secondary RNA structure of gurken $5^{\prime}$ UTR, and the function of a closely located RNA element important for its localization (Saunders and Cohen 1999). Splicing of the first intron of gurken is also likely to facilitate Gurken protein expression, as deletion of the first intron of gurken suppresses the dorsalization phenotype associated with increased copy number of gurken gene without affecting the levels of gurken
mRNA. Our results therefore fully support the role of gurken $5^{\prime}$ UTR in mRNA localization within the oocyte, and strongly suggest that Salsa-dependent splicing of the first intron of gurken mRNA is important for the correct expression and function of this gene.

\section{Salsa facilitates efficient splicing of small first introns}

The precise function of human Aquarius in splicing is still poorly understood. This RNA helicase is recruited to the spliceosome as a pentameric complex known as intronbinding complex (IBC), which also contains hSyf1 (also known as Xab2), hlsy1, CypE, and CCDC16 (De et al. 2015). Coimmunoprecipitation experiments suggest a large interaction interface between IBC and U2 snRNP, within the activated spliceosome ( $\mathrm{B}^{\text {act }}$ stage) and just before the first splicing reaction. Although Aquarius ability to bind and hydrolyze ATP is important for spliceosome activation and splicing efficiency, the role of its RNA unwinding activity is less clear.

Our work has identified a small subset of introns whose splicing is particularly sensitive to depletion of Salsa (the Drosophila ortholog of human Aquarius). The fact that splicing was only affected in a small number of introns is consistent with the observation that immunodepletion of human Aquarius from nuclear extracts only weakly impaired splicing in vitro (De et al. 2015). This suggests that although this RNA helicase is apparently not critical for overall splicing, during female gametogenesis there is a subset of introns whose efficient removal relies on the function of this enzyme.

Analysis of the introns whose splicing was sensitive to Salsa depletion showed a clear bias for small first introns with weak 3 'splice sites, independently of their distance to the transcription start site (TSS), 5'splice site strength and GC content. The bias for small introns suggests that Salsa is mostly rate-limiting when introns are recognized by intron definition (Pai et al. 2017), where the initial pairing between $\mathrm{U} 1$ and $\mathrm{U} 2$ snRNPs occurs across the intron. Furthermore, the bias for introns with weak 3'splice sites is in accordance with the extensive interaction between IBC and U2 snRNP in the activated spliceosome, and implies that depletion of Salsa is likely to impair, at least in a subset of introns, U2 snRNP function during splicing. The absence of any detectable bias for short distances between the TSS and 5'splice site, when evaluating affected and control first introns, or any bias for weak 5 'splice site strength, suggests that Salsa is not likely rate-limiting for Cap-Binding Complex-mediated splicing (Qiu et al. 2007).

Drosophila first introns are more likely to be cotranscriptionally retained than internal and terminal introns (Khodor et al. 2011). This is not consistent with the kinetic competition model (Bentley 2014), where the fastest processes are the ones most likely to occur, suggesting additional 
constraints to first intron splicing. Although the precise nature of such constraints is still poorly understood, binding of transcriptional initiation factors to the 5'splice site-associated U1snRNP (Damgaard et al. 2008; Bentley 2014) potentially restricts splicing efficiency, as it might impair the initial pairing between U1 and U2 snRNPs. Our working hypothesis is that Salsa is required for splicing of small first introns with weak 3'splice site because this enzyme facilitates U2 snRNP function, minimizing the interference effect of transcriptional initiation factors on splicing. Future work will help define the function of this RNA helicase and its contribution for differential gene expression during development.

\section{MATERIALS AND METHODS}

\section{Fly husbandry}

All flies were raised at $25^{\circ} \mathrm{C}$, unless otherwise indicated, using standard techniques.

\section{Drosophila RNAi stocks}

Unless indicated, all stocks are available at the Bloomington Drosophila Stock Center. Depletion of Salsa was obtained using three different nonoverlapping dsRNA hairpins. salsa RNAi-2 stock is available in BDSC (Bloomington number 55172; hairpin reference; P \{TRiP.HMC03852\}attP40; Map: Chr 2,25C6, 2L: 5108448..5108448.), whereas salsa RNAi-1 and salsa RNAi-3 were custom made.

\section{Generation of nonoverlapping salsa RNA $i$ (salsa RNAi-1 and RNAi-3)}

We designed two nonoverlapping RNAi hairpins against salsa (CG31368) using an algorithm that minimizes off target effects (Vert et al. 2006). Based on a miR1 scaffold, for the top strand oligo (TS) of salsa, ctagcagt nucleotides were added to the $5^{\prime}$ end of the passenger strand DNA and tagttatattcaagcata nucleotides were added between passenger strand DNA and the guide strand DNA. In the end gcg nucleotides were added to the $3^{\prime}$ end of guide strand DNA. The top strand oligo (TS) of salsa 1 and salsa 3 are the following:

salsa RNAi-1 TS: ctagcagtCGCTTGGATATGGACGATCTAtagtta tattcaagcataTAGATCGTCCATATCCAAGCGgcg

salsa RNAi-3 TS: ctagcagtCCACGATTATCTCCTACGCAAtagtt atattcaagcataTTGCGTAGGAGATAATCGTGGgcg

For the bottom strand oligo (BS) of salsa, aattcgc nucleotides were added to the $5^{\prime}$ end of the passenger strand DNA, and tatgcttgaatataacta nucleotides were added between passenger strand DNA and the guide strand DNA. In the end actg nucleotides were added to the $3^{\prime}$ end of guide strand DNA. The bottom strand oligo (BS) of salsa 1 and salsa 3 are the following: salsa RNAi-1 BS: aattcgcCGCTTGGATATGGACGATCTAtatgctt gaatataactaTAGATCGTCCATATCCAAGCGactg

salsa RNAi-3 BS: aattcgcCCACGATTATCTCCTACGCAAtatgctt gaatataactaTTGCGTAGGAGATAATCGTGGactg

Annealing the top and bottom strand oligos: $10 \mu \mathrm{L}$ top strand oligo $(10 \mu \mathrm{M})$ and $10 \mu \mathrm{L}$ bottom strand oligo $(10 \mu \mathrm{M})$ were added into $80 \mu \mathrm{L}$ annealing buffer $(10 \mathrm{mM}$ Tris- $\mathrm{HCl}, \mathrm{pH} 7.5,0.1 \mathrm{M} \mathrm{NaCl}$, $1 \mathrm{mM}$ EDTA). The reaction mix was incubated at $95^{\circ} \mathrm{C}$ for $5 \mathrm{~min}$, and then, slowly cooled down to room temperature. The resulting DNA fragment has overhangs for Nhel and EcoRI. The resulting DNA fragments were directly cloned into a VALIUM22 vector, which has been linearized by $\mathrm{Nhel}$ and EcoRl enzymes. For the DNA ligation reaction, $6 \mu \mathrm{L}$ of the annealing product mixed with $2 \mu \mathrm{L}$ of $10 \times$ ligation buffer and $1 \mu \mathrm{L}$ of T4 DNA ligase (1 $\mathrm{U} / \mu \mathrm{L}$ ). Finally, $1 \mu \mathrm{L}$ of $40 \mathrm{ng} / \mu \mathrm{L}$ backbone (gel purified VALIUM22 digested with Nhel and EcoRI) was added to the final reaction. The final volume of $20 \mu \mathrm{L}$ was made up with ddH20, mixed carefully and incubated overnight at $16^{\circ} \mathrm{C}$. The reaction was stored at $-20^{\circ} \mathrm{C}$, until further use.

For transformation, $10 \mu \mathrm{L}$ of ligation reaction was transformed into $50 \mu \mathrm{L}$ TOP10 competent cells using the electroporation method. Clones were selected through PCR using the standard primers for pVALIUM22 (Supplemental Table S3). The correct shRNA constructs were further confirmed by sequencing. The primer used for sequencing is shown in Supplemental Table S3. Plasmid amplification and isolation of the correct shRNA constructs was done using the standard protocol from the NZY Miniprep isolation kit. (NZY Tech, Genes and Enzymes). For production of transgenic Drosophila stocks, isolated plasmids were sent for injection (BestGene, Chino Hills). All transgenic stocks were confirmed by DNA sequencing.

\section{Germline-specific depletion of Salsa}

Salsa was specifically depleted within the female germline by using the germline-specific driver nanos-Gal4 (nos-Gal4) (Van Doren et al. 1998) and the upstream activating sequence (UAS)/Gal4 system (Brand and Perrimon 1993; Rorth 1998; Ni et al. 2011).

\section{Ventralized eggshell phenotypes}

Flies were cultured at $25^{\circ} \mathrm{C}$ and transferred to a new tube every $3 \mathrm{~d}$. Zero to three days old F1 females $(n=20)$ were crossed with wild-type males $(n=5)$ and added to an egg collection cage supplemented with fresh yeast. Ventralized eggshell phenotype was scored at least $2 \mathrm{~d}$ after assembly of the collection cage (for optimal egg laying) and using fresh egg collections (4-5 h) to facilitate unequivocal scoring.

\section{Egg hatching}

One to three days old F1 females $(n=20)$ were crossed with wildtype males $(n=5)$ and added to an egg collection cage supplemented with fresh yeast. Eggs were collected using freshly prepared apple juice plates. Plates were incubated for $48 \mathrm{~h}$ at $25^{\circ} \mathrm{C}$ and egg hatching was scored. 


\section{Genomic construct of gurken}

Drosophila melanogaster Flybase genome was used as reference for all gurken genomic constructs. Used sequences are identical to the most up-do-date release (FB2020_03, released Jun 16, 2020). All constructs include 600 nt upstream of the annotated transcriptional start site (endogenous promoter) and $200 \mathrm{nt}$ downstream from the transcriptional end site. All constructs were cloned into a pWallium22 plasmid and integrated in the genome using phiC31 mediated integration. All constructs were integrated in the attP2 docking site. Genomic construct of gurken lacking its first intron ( $g r k^{\text {no }}$ 1st intron) is identical to wild-type construct $\left(g k^{W T}\right)$, except that the first intron was fully deleted and the first and second exons fused in-frame. Genomic construct of gurken with first intron splice site mutations ( $g r k^{\text {splice site mutant }}$ ) is identical to wild-type construct, except that the first intron $5^{\prime}$ and $3^{\prime}$ splice sites (respectively, GT and AG) were both mutated to TT. DNA synthesis was done by GenScript Biotech (Piscataway). For production of transgenic Drosophila stocks, isolated plasmids were sent for injection (BestGene). All transgenic stocks were confirmed by DNA sequencing.

\section{Ovaries immunostaining}

Adult ovaries (20 ovary pairs per sample per experiment) were processed according to standard procedures (Ferreira et al. 2014; Navarro-Costa et al. 2016; Prudencio et al. 2018). All incubation steps involve a gentle mix with an orbital or nutator mixer. Briefly, ovaries were dissected from 2-4-d-old females in ice cold Phosphate-buffered saline (PBS) and fixed for $20 \mathrm{~min}$ with a 3:1 mix of heptane (Fluka) and fixative aqueous mix. The fixative mix consisted of $4 \%$ formaldehyde (Polysciences) in PBS $+0.5 \%$ NP-40 (Sigma) solution. Following three 10 min washes in PBST (PBS $+0.2 \%$ Tween 20 ), ovarioles were gently detached with a tungsten needle. Ovaries were subsequently blocked for $1 \mathrm{~h}$ in PBS supplemented with 1\% Triton X-100 (Sigma), 1\% (w/v) bovine serum albumin (BSA; Sigma), and 1\% (w/v) donkey serum (Sigma). Primary antibody was performed overnight at $4{ }^{\circ} \mathrm{C}$ in PBST supplemented with $1 \%$ BSA and $1 \%$ donkey serum (BBT solution). After three 10 min washes in PBST, ovaries were incubated for $1 \mathrm{~h}$ at the room temperature with the appropriate secondary antibodies diluted in BBT solution. DNA was subsequently stained for $30 \mathrm{~min}$ at the room temperature using 1:10.000 DAPI in PBST. Prior to mounting, ovaries were washed three times, 10 min each, with PBST. Ovaries were mounted in Dako Faramount Aqueous Mounting Medium (Dako) and were visualized using a Zeiss LSM710 Confocal microscope.

\section{Quantification of ovaries Gurken immunostaining}

For quantification of Gurken signal at the dorsal anterior region of the oocyte, maximum intensity projections of serial confocal optical sections of individual egg chambers stained with an antiGurken mouse antibody (Queenan et al. 1999) (clone 1D12; dilution 1/30) were obtained using the Image J program (Grouped Zprojector, maximum pixel intensity). The average Gurken signal intensity within three oocyte dorsal anterior regions with highest levels of localized Gurken was obtained using ImageJ software. For each egg chamber, obtained values were divided by the re- spective average background signal intensity value obtained within three cytoplasmic regions of the nurse cells or the oocyte.

\section{Preparation of a DIG-labelled gurken probe}

A plasmid carrying a gurken cDNA sequence (NeumanSilberberg and Schupbach 1993) was linearized with Sal I restriction enzyme and analyzed on agarose gel electrophoresis. The linearized plasmid was isolated and purified with a gel purification kit (Promega), using standard procedures. The purified linearized plasmid was subsequently quantified with a spectrophotometer (Thermo Scientific NanoDrop 2000). Synthesis of DIG-labeled antisense gurken RNA probes, was made according to the following reaction: $2 \mu \mathrm{L}$ of linearized plasmid $(1 \mu \mathrm{g})$ was mixed with the following reagents, in this order and at room temperature: $1 \mu \mathrm{L}$ of 10x transcription buffer (Roche), $1 \mu \mathrm{L}$ DIG-NTP mix (Roche), $0.3 \mu \mathrm{L}$ of RNase inhibitor (Roche) and $1 \mu \mathrm{L}$ T7 RNA polymerase (10 U/ $\mu \mathrm{L}$; Roche) (de Las Heras et al. 2009). The final reaction volume was set up to $10 \mu \mathrm{l}$ of DEPC water. The final reaction mixture was subsequently incubated at $37^{\circ} \mathrm{C}$ for $2 \mathrm{~h}$. Subsequently, $40 \mu \mathrm{L}$ DEPC water and $50 \mu \mathrm{L} 2 \times$ Carbonate Buffer (120 mM-Na $\mathrm{CO}_{3} ; 80$ $\mathrm{mM} \mathrm{NaHcO}_{3}$ at $\mathrm{pH}$ 10.2) were added to the probes and the mix was incubated at $65^{\circ} \mathrm{C}$ for $40 \mathrm{~min}$. Hydrolyzed probes were precipitated by adding $100 \mu \mathrm{L} 0.2 \mathrm{M} \mathrm{NaAc}(\mathrm{pH} 6), 10 \mu \mathrm{L}$ of $4 \mathrm{M}$ $\mathrm{LiCl}, 10 \mu \mathrm{L}$ of tRNA (Roche; stock solution $20 \mathrm{mg} / \mu \mathrm{L}$ ), and $600 \mu \mathrm{L}$ of absolute ethanol, on a $-20^{\circ} \mathrm{C}$ overnight incubation. Mix was centrifugated at $4^{\circ} \mathrm{C}$ for $15 \mathrm{~min}$. Pellet was washed twice with $70 \% \mathrm{EtOH}$, dried in air (10 min), and dissolved in Hybridization MIX buffer ( $50 \%$ formamide, $5 \times$ SSC solution, $0.1 \%$ Tween-20, $100 \mu \mathrm{g} / \mathrm{mL}$ heparin, $100 \mu \mathrm{g} / \mathrm{mL}$ ssDNA). Probes were stored at $-20^{\circ} \mathrm{C}$ before use.

\section{Fluorescent in situ hybridization of Drosophila ovaries}

Adult ovaries from 2-4-d-old females were dissected and fixed according to standard procedures (Ferreira et al. 2014; NavarroCosta et al. 2016; Prudencio et al. 2018). All incubation steps involve a gentle mix with a nutator mixer. Ovaries were dissected from 2-4-d-old females in ice cold Phosphate-buffered saline (PBS) and fixed for 20 min with a 3:1 mix of heptane (Fluka) and fixative aqueous mix. The fixative mix consisted of $4 \%$ formaldehyde (Polysciences) in PBS + 0.5\% NP-40 (Sigma) solution. After fix, ovarioles were gently teased apart with forceps and dehydrated in methanol by washes of 5 min with the following solutions: $30 \%$ methanol/PBT (PBS + 0.2\% Tween-20), 50\% methanol/PBT and $70 \%$ of methanol/PBT. Ovaries were stored in $100 \%$ methanol at $-20^{\circ} \mathrm{C}$ before usage.

Prior to usage, ovaries were rehydrated by washes with $70 \%$ Methanol/PBT; 50\% Methanol/PBT and 30\% Methanol/PBT. After rehydration, ovaries were washed with PBS $+0.1 \%$ Tween20, for $5 \mathrm{~min}$, three times and transferred to a prehybridization buffer (40\% formamide, $4 \times$ SSC (20× SSC [RNase free], $0.1 \%$ Tween 20) and incubated for $1 \mathrm{~h}$ at the room temperature. Ovaries were then transferred into $200 \mu \mathrm{L}$ hybridization buffer (50\% formamide, $5 \times$ SSC [20× SSC (RNase free)], 0.1\% Tween 20, $100 \mu \mathrm{g} / \mathrm{mL}$ heparin, $100 \mu \mathrm{g} / \mathrm{mL}$ ssDNA) and incubated for $1 \mathrm{~h}$ at $55^{\circ} \mathrm{C}$. RNA probes were diluted at 5:100 in a preheated hybridization buffer. After removal of the hybridization solution, 


\section{Rathore et al.}

$50 \mu \mathrm{L}$ of preheated diluted probes were added to the ovaries for overnight incubation at $55^{\circ} \mathrm{C}$. The following day, used probes were collected, and ovaries were transferred to $1 \mathrm{~mL}$ prehybridization solution for a $30 \mathrm{~min}$ incubation at $55^{\circ} \mathrm{C}$. They were subsequently washed five times with $1 \mathrm{ml}$ of PBS $+0.1 \%$ Tween-20 for 30 min each time, at the room temperature. After washes, ovaries were incubated in Roche Blocking Buffer (1:10 in PBS-0.1\% Tween-20) for $1 \mathrm{~h}$ at the room temperature. The mouse anti-Dig (1:400) was diluted in Roche Blocking Buffer (1:10 in PBS-0.1\% Tween-20) and incubated overnight at $4^{\circ} \mathrm{C}$ in a rocking shaker. The ovaries were washed three times with $1 \mathrm{~mL}$ PBS-0.1\% Tween-20 for 10 min each at the room temperature and incubated with Roche Blocking Buffer as above for $30 \mathrm{~min}$ at the room temperature, following incubation ( $1 \mathrm{~h}$ at RT) with secondary antibody anti-mouse-Cy3 (1:1000) diluted in Roche Blocking Buffer as above. Ovaries were washed three times with $1 \mathrm{~mL}$ PBS-0,1\% Tween-20, for 5 min each time, at room temperature. DNA was subsequently stained for $10 \mathrm{~min}$ at the room temperature using 1:10.000 DAPI in PBS-0.1\% Tween-20. Prior to mounting, ovaries were washed in PBS-0.1\% Tween-20 three times, 5 min each, then rinsed with PBS. Ovaries were mounted in Vectashield mounting medium and they were visualized using a Zeiss LSM710 Confocal microscope.

\section{Quantification of gurken mRNA localization}

For semi-quantitative quantification of dorsal-anterior localization of gurken mRNA, stage 8/9 oocytes were divided it into three different classes based on the gurken mRNA dorsal-anterior signal near to the oocyte nucleus: (a) normal dorsal-anterior localization of gurken mRNA, with a strong signal distributed in the periphery of the oocyte nucleus; (b) partial dorsal-anterior localization, with weaker but clearly detectable gurken mRNA nearby the periphery of the oocyte nucleus; (c) absence/almost absence of dorsal-anterior localization, with undetectable or hardly detectable gurken mRNA signal nearby the periphery of the oocyte nucleus.

\section{Real-time quantitative PCR (real-time qPCR)}

\section{Optimization of primers efficiency for target genes and reference genes}

Primers were designed using PrimerBLAST (NCBI) and optimized to an equal annealing temperature $55^{\circ} \mathrm{C}$. Primer efficiencies were initially tested with Drosophila genomic DNA (gDNA). Fivefold serial dilutions of gDNA were made $(40,8,1.6,0.32$, and 0.064 $\mathrm{ng})$, and primer efficiencies for both target genes and reference genes were tested. Standard curves were constructed by the Cycle of threshold $\left(C_{t}\right)$ ( $y$-axis) versus log gDNA dilution ( $x$-axis). The primer efficiency (E) of one cycle in the exponential phase was calculated according to the equation: $E=10^{(-1 / \text { slope })}-1$ (Nolan et al. 2006). Efficiency and regression curves for each primer set are shown in Supplemental Table S4. Specificity of primer pair amplification was confirmed by melting curve analysis and the $\mathrm{Ct}$ values were obtained from the dynamic range of the standard curves. Only primer sets with specificity and good efficiency were used for subsequent RT-qPCR analysis.

\section{mRNA extraction and CDNA synthesis}

Total RNA was extracted from 0-1 h embryos (after egg laying) or from 2-4-d-old adult female ovaries (after pupae eclosion), whose female germline was specifically depleted for salsa (salsa RNAi) or negative control (mCherry RNAi). Extraction was performed following standard procedures (PureLink RNA Mini Kit, Ambion). Genomic DNA was removed from RNA samples using PureLink DNase (Invitrogen) on-column method. Experion Electrophoresis (Bio-Rad) was used to assess the integrity and quantity of isolated RNA. Isolated RNA with less than 8 RQI was not considered for reverse transcription with iScript (as described above) and further Real-Time qPCR analysis. Three technical replicates were performed for each sample. A technical replicate corresponds to three different cDNAs synthesized from the same isolated RNA. Biological replicates correspond to RNAs obtained from distinct biological samples.

\section{Quantitative PCR reaction ( $q P C R$ )}

The equivalent to $4 \mathrm{ng}$ cDNA was used as template in each qPCR reaction. qPCR reactions were performed on a CFX96 Real-Time system (Bio-Rad) using SsoFast EvaGreen Supermix (Bio-Rad). Two reference genes (Actin and GAPDH) were used for normalization. "no template," "no RT," and "NEG" were used as negative controls for testing the qPCR reaction mixture contamination. Genomic DNA was used as positive control. For each reaction, the RT-qPCR master mix included $10 \mu \mathrm{L}$ of $2 \times$ EvaGreen mix, $1 \mu \mathrm{L}$ of forward primer $(10 \mu \mathrm{M}), 1 \mu \mathrm{L}$ of reverse primer $(10 \mu \mathrm{M})$, and $4 \mu \mathrm{L}$ of nuclease-free water. The master mix $(16 \mu \mathrm{L})$ was added to a well of 96-multiwell plate (Bio-Rad) followed by the addition (when appropriate) of $4 \mu \mathrm{L}$ CDNA (4 ng). PCR protocol: denaturation program $\left(95^{\circ} \mathrm{C}\right.$ for $30 \mathrm{sec}$ ), amplification program repeated for 60 cycles (denaturation: $95^{\circ} \mathrm{C}$ for $5 \mathrm{sec}$, annealing: $55^{\circ} \mathrm{C}$ for $5 \mathrm{sec}+$ plate read for fluorescence measurement), melting curve program $\left(65^{\circ} \mathrm{C}\right.$ to $95^{\circ} \mathrm{C}$ with $0.5^{\circ} \mathrm{C}$ increments, for $5 \mathrm{sec}+$ plate read for fluorescence measurement), and cooling program to $4^{\circ} \mathrm{C}$.

\section{Expression analysis}

The threshold cycle $(\mathrm{C} t)$ of each gene transcript was determined by setting the threshold line above background levels in the linear region of the exponential curve before the gene expression levels were measured. The baseline and fluorescence signals are adjusted automatically by the CFX96 Real-Time machine software (default parameters) to calculate the $\Delta$ Ct value (Schmittgen and Livak 2008). The relative expression ratio (RE) was calculated using the difference between $\Delta \mathrm{Ct}$ value of negative control (mCherry RNAi) and salsa RNAi, also known as the $2^{-\Delta \Delta \mathrm{Ct}}$ method.

$$
\mathrm{RE}=2^{\left(-\left(\Delta \mathrm{C}_{\mathrm{sample}}(\text { target-reference })-\Delta \mathrm{Ct}_{\text {control }}(\text { target-reference) }) .\right.\right.}
$$

$\Delta \mathrm{Ct}_{\text {sample }}$ is the $\mathrm{Ct}$ difference of target-reference genes in salsa $\mathrm{RNAi} ; \Delta \mathrm{Ct}_{\text {control }}$ is the $\mathrm{Ct}$ difference of target-reference genes in control RNAi.

Total expression levels of the genes of interest were calculated by the mean of $\mathrm{Ct}$ values normalized to the expression levels of two reference genes (Actin and GAPDH) using the geNorm method (Vandesompele et al. 2002). Mean and standard deviation (SD) of RE values were calculated from three biological replicates. 


\section{Reverse transcription droplet digital PCR (RT-ddPCR)}

The accurate quantification of the primary transcript and spliced isoform was achieved by one-step RT-ddPCR (Bio-Rad), with the Bio-Rad QX200 Droplet Digital PCR System and One-Step RTddPCR Advanced Kit for Probes, according to manufacturer's instructions. In short, $100 \mathrm{ng}$ of purified total RNA, was mixed with $900 \mathrm{mM}$ primers, $250 \mathrm{nM}$ probes and the enzymes Reverse transcriptase and DNA polymerase and then partitioned into thousands of individual water-oil emulsion droplets. Primer-specific reverse transcription was carried out inside each droplet, followed by PCR amplification and Taqman probe detection. In a C1000 thermal cycler (Bio-Rad), reverse transcription was carried out for $60 \mathrm{~min}$ at $50^{\circ} \mathrm{C}$, then the RT enzyme was denatured and simultaneously the DNA pol enzyme was activated by 10 min incubation at $95^{\circ} \mathrm{C}$, followed by 46 cycles of denaturation for $35 \mathrm{sec}$ at $95^{\circ} \mathrm{C}$ and annealing/elongation for $1 \mathrm{~min}$ at $60^{\circ} \mathrm{C}$, and a final inactivation step for $10 \mathrm{~min}$ at $98^{\circ} \mathrm{C}$. Primers and probes (IDT, Integrated DNA Technologies) were designed with IDT software tools available online. Unspliced GRK, exon1-intron 1: forward -TATAGCAGCTCCAGTACGTC, reverse-CTACACACTTGCAT CTCCTTG, probe-TTGTTTCGTGTGTGTGCGTTCGTG; spliced GRK, exon1-exon2: forward-CCATATAGCAGCTCCATAAAAT CC, reverse-TAAACGATCGAGGGATCGAG, probe-ATGTT TCAGCTTCTGTTGCGACGC; reference GRK, exon3: forwardCGACAAGGAGACAGAGATTCAG, reverse-TAACGCAGAGG CAGGAATG, probe-TGCCCTGCAGCGAAGCTTACAATA. Specific target sequences were detected with 6-FAM/ZEN/ IBFQ labeled probes and the reference target was detected with a HEX/ZEN/IBFQ labeled probe. Positive fluorescent droplets were carrying the target RNA sequence. Individual droplet fluorescence was read in a QX200 Droplet reader and data was analyzed using Quantasoft Version 1.7.4.0917. Manual thresholds were applied to define positive fluorescent signal. A nontemplate control was included for each primer set. Each purified RNA sample was tested by a non-RT control with the pre-mRNA primer set, with no RT enzyme in the mix. Graphs and statistical t-tests were made using GraphPad Prism 8.2.

One advantage of One-Step ddPCR is that reverse transcription and amplification processes are carried out inside each individual droplet, avoiding bias. The primer-specific reverse transcription abrogates any reverse transcriptase bias and increases sensitivity. The separation of RNA in compartments avoids competition between splicing isoforms and therefore favors unbiased amplification of under-represented forms. The results of ddPCR are absolute and independent of primer amplification efficiency, with no need for efficiency determination or calibration curves.

\section{Protein extraction}

Zero to one hour embryos (after egg laying) or 2-4-d-old adult female ovaries (after pupae eclosion), whose female germline was specifically depleted for salsa (salsa RNAi) or negative control (mCherry RNAi), were homogenized with a pestle in ice-cold NB-lysis buffer (50 mM Tris [pH 7.5], $150 \mathrm{mM} \mathrm{NaCl}, 2 \mathrm{mM}$ EDTA, 0.01\% NP-40 [lgepal], 2 mM DTT, $10 \mathrm{mM} \mathrm{NaF}$, and protease inhibitors [complete protease inhibitor cocktail, Roche]). The sample was centrifuged three times at $14,000 \mathrm{rpm}$, at $4^{\circ} \mathrm{C}$, and for $5 \mathrm{~min}$. Between each centrifugation, the supernatant was carefully collected into a new tube, avoiding the pellet and the upper lipid-rich layer. Bradford protein microassay (Bio-Rad) was performed to quantify the total amount of protein, and whenever needed, the total protein extract was frozen with liquid nitrogen and kept at $-80^{\circ} \mathrm{C}$ until further usage.

\section{Western blot analysis}

For western blot analysis, total protein extracts were boiled for $5 \mathrm{~min}$ at $95^{\circ} \mathrm{C}$ in $2 \times$ Laemmli buffer (Sigma). Ten micrograms of protein were loaded per lane, and run in a SDS polyacrylamide gel electrophoresis gel ( $6 \%$ or $12 \%)$. Proteins were subsequently transferred onto Hybond-ECL nitrocellulose membrane (Amersham) using a Bio-Rad wet transfer apparatus (100 V for $60 \mathrm{~min}$ ). Western blotting was performed using standard procedures. Briefly, the Hybond-ECL membrane was blocked overnight with $5 \%$ nonfat milk in PBS-T (PBS $+0.1 \%$ Tween-20) at $4{ }^{\circ} \mathrm{C}$ with shaking. Primary antibodies were incubated overnight in $1 \%$ nonfat milk in PBS-T with gentle shaking at $4^{\circ} \mathrm{C}$. Membranes were washed three times with PBS-T, for $15 \mathrm{~min}$ at room temperature and with strong shaking. Secondary antibodies were incubated for $2 \mathrm{~h}$ in $1 \%$ nonfat milk in PBS-T at the room temperature with gentle shaking. After three washes in PBS-T, for $5 \mathrm{~min}$ at room temperature, and one quick wash with PBS, proteins of interest were detected with an ECL Plus Western blotting detection system (GE Healthcare) and an ECL Hyperfilm (Amersham).

\section{Expression of carboxy-terminal Myc-tagged Salsa}

\section{Cloning of Myc-tagged Salsa}

For cloning of a carboxy-terminal Myc-tagged Salsa, the open reading frame of CG31368 was amplified by Expand High Fidelity PCR System (Roche) from the cDNA clone RE 35509 (BDGP). Please note that a point mutation present in the original cDNA clone RE35509 was corrected by site-directed mutagenesis using the publically available Flybase sequence of CG31368 as reference. The QuikChange Site-Directed Mutagenesis Kit (Agilent Technologies) was used for site-directed mutagenesis, according to manufacturer's standard protocol. For primers sequence see Supplemental Table S3. For PCR amplification we used the High Fidelity PCR system (Roche), with the following conditions: initial denaturation for the first cycle $\left(95^{\circ} \mathrm{C}\right.$ for 2 $\mathrm{min}$ ), primary amplification program repeated for 10 cycles (denaturation: $94^{\circ} \mathrm{C}$ for $15 \mathrm{sec}$, annealing: $55^{\circ} \mathrm{C}$ for $30 \mathrm{sec}$ and elongation: $68^{\circ} \mathrm{C}$ for $4 \mathrm{~min}$ ), secondary amplification program repeated for 10 cycles (denaturation: $94^{\circ} \mathrm{C}$ for $15 \mathrm{sec}$, annealing: $55^{\circ} \mathrm{C}$ for $30 \mathrm{sec}$ and elongation: $72^{\circ} \mathrm{C}$ for $4 \mathrm{~min}$ ), final elongation for one cycle $\left(72^{\circ} \mathrm{C}\right.$ for $\left.10 \mathrm{~min}\right)$, and cooling at $4^{\circ} \mathrm{C}$ for an unlimited time. The PCR product was cloned into PAMW plasmid (Gateway) using the Gateway system (Invitrogen).

\section{Culture of Drosophila S2 cells}

Drosophila Schneider 2 (S2) cells were cultured in Schneider's Drosophila complete medium: Schneider's insect medium (Sigma), supplemented with $1 \times$ L-glutamine, 1x PenStrep, and $10 \%$ Fetal bovine serum (Invitrogen) at $25^{\circ} \mathrm{C}$. 


\section{Rathore et al.}

\section{Transfection of Myc-tagged Salsa}

Transient transfection in Drosophila S2 cells with a carboxy-terminal Myc-tagged Salsa construct was done using FuGENE HD Transfection Reagent and standard procedures (Promega). Briefly, a mix of $100 \mu \mathrm{L}$ of Serum Free Medium (SFM), $400 \mathrm{ng}$ of DNA, and $4 \mu \mathrm{L}$ of Fugene HD were incubated at the room temperature for $15 \mathrm{~min}$. Meanwhile, cells were plated into six well plates at the concentration of $2.5 \times 10^{6}$ cells/well in serum free medium. The mix (DNA and Fugene) was added drop by drop on the top of cells. To stop the transfection reaction, $2 \mathrm{~mL}$ complete medium (with 10\% Fetal bovine Serum) was added to the cells after $4 \mathrm{~h}$ of incubation at $25^{\circ} \mathrm{C}$ and cells were incubated for $48 \mathrm{~h}$ at $25^{\circ} \mathrm{C}$.

\section{Coimmunoprecipitation}

Coimmunoprecipitation was done using protein extracts from Drosophila S2 cells expressing carboxy-terminal Myc-tagged Salsa or a negative control (empty Myc-plasmid). Briefly, $1 \mathrm{mg}$ of total protein extract was diluted in $1 \mathrm{~mL}$ of ice-cold NB-lysis buffer, and it was incubated with anti-c-Myc Magnetic beads (Invitrogen) for $1 \mathrm{~h}$ at $4^{\circ} \mathrm{C}$. Anti-c-Myc magnetic beads were then washed three times with NB-lysis buffer and resuspended in $100 \mu \mathrm{L}$ NB-lysis buffer. Half of each sample was boiled for 5 min at $95^{\circ} \mathrm{C}$ with $2 \times$ Laemmli buffer (Sigma) for further western blot analysis (no RNase A-treated samples). The remaining half was incubated with RNase A (Thermo Fisher) for $30 \mathrm{~min}$ at $37^{\circ} \mathrm{C}$. Beads were further washed three times with NB-lysis buffer and boiled for $5 \mathrm{~min}$ at $95^{\circ} \mathrm{C}$ with $2 \times$ Laemmli buffer (Sigma).

\section{RNA-seq analysis}

\section{RNA isolation}

Total RNA was extracted from 2-4-d-old adult female ovaries (after pupae eclosion), whose female germline was specifically depleted for salsa (salsa RNAi) or negative control (mCherry RNAi). Extraction was performed following standard procedures (PureLink RNA Mini Kit, Ambion). Genomic DNA was removed from RNA samples using PureLink DNase (Invitrogen) on-column method. Experion Electrophoresis (Bio-Rad) was used to assess the integrity and quantity of isolated RNA.

\section{Preparation of cDNA library and RNA-seq}

After the QC procedures, mRNA from eukaryotic organisms is enriched using oligo(dT) beads. First, the mRNA is fragmented randomly to short fragments of 250-300 bp in fragmentation buffer, then cDNA is synthesized by using mRNA template and random hexamers primer. After the first strand was synthesized, a custom second-strand synthesis buffer (Illumina), dNTPs (dUTP, dATP, dGTP, and dCTP) and DNA polymerase I were added to initiate the second-strand synthesis. Then followed by purification by AMPure XP beads, terminal repair, polyadenylation, sequencing adapter ligation, size selection, and degradation of second-strand U-contained cDNA by the USER enzyme. The strand-specific cDNA library was generated after the final PCR enrichment. cDNA library preparation and HiSeq paired-end sequencing (150 nt) was performed by Novogene

\section{Differential intron retention analysis}

Overall quality of raw RNA-seq data was analyzed using fastqc version 0.11 .5 (https://www.bioinformatics.babraham.ac.uk/ projects/fastqc/) on the associated FASTO files. vast-tools (Braunschweig et al. 2014; Irimia et al. 2014; Tapial et al. 2017) version 2.0.0 was used for quantification of alternative sequence inclusion levels from FASTQ files using VAST-DB annotation for Drosophila melanogaster genome assembly dm6 (Tapial et al. 2017; Torres-Mendez et al. 2019). To ensure intron retention quantification with sufficient and reliable read coverage, we considered only vast-tools' events with a minimum mappability-corrected read coverage score of "OK" across all samples, corresponding to at least 20 mappability-corrected reads mapping either to the sum of skipping splice junctions or to one of the two inclusion exon-intron junctions and at least 15 of such reads mapping to the other inclusion splice junctions, as described in vast-tools's GitHub description page (https ://github.com/vastgroup/vast-tools). Also, only intron retention events without statistically significant evidence for a high imbalance in read counts between both upstream and downstream exon-intron junctions and the intron body (Braunschweig et al. 2014) (binomial test's $P$-value $\geq 0.05$ ) for all samples were considered. Percent intron retention (PIR) (Braunschweig et al. 2014) estimates are quantified as the ratio between the average of exon-intron junction reads that support intron inclusion (\#inc) and the sum of these with exon-exon junction reads, supporting intron skipping (\#exc).

Precision of PIR estimates from their supporting read coverage (\#inc and \#exc) was modeled using the beta distribution (conjugate prior probability distribution for the binomial), constrained to $[0,1]$ and defined by shape parameters $\alpha$ and $\beta$ and a mean of $\alpha /(\alpha+\beta)$. Given that, for $\alpha, \beta \neq 0$ for the same mean, beta distributions get narrower with increasing shape parameters, emitting points from a beta distribution with $\alpha=\#$ inc and $\beta=\#$ exc allows the scattering of emitted values to serve as a surrogate for that PIR's dispersion (given the original read coverage supporting it), while the distribution's mean value, \#inc/(\#inc + \#exc), is an approximation of the empirical PIR. For each considered intron retention event with nonzero \#inc and \#exc, the R function rbeta was used to emit, for each sample, 500 values from a beta distribution with shape parameters $\alpha=\#$ inc and $\beta=\#$ exc. However, while \#inc or \#exc can be equal to zero, beta distributions with $\alpha \operatorname{or} \beta=0$ are single valued as 0 or 1 , respectively, and are not appropriate to model inclusion levels. Therefore, an increment factor (incr) proportional to global coverage was added to zero \#inc $(\mathrm{PIR}=0)$ or \#exc (PIR = 1) read counts, followed by emission, using rbeta, of 500 points from a beta distribution with $\alpha=\#$ inc + incr and $\beta=\#$ exc + incr. Increment factors per coverage were set as the maximum value between 0.01 and 1 such that not more than $5 \%$ of simulated 500 -point beta distributions with $\alpha=$ incr and $\beta=$ coverage have a median that shows a deviation from theoretical PIR larger than 0.01 .

For each considered event, rbeta-emitted values were grouped per condition (control and salsa RNAi), with their median values set as the respective summary PIRs (PIR beta). The difference between these, $\Delta P I R_{\text {beta }}=P R_{\text {salsa }}$ RNAi $-P R_{\text {control, was used as the }}$ magnitude of differential intron inclusion. The significance of each $\Delta \mathrm{PIR}_{\text {beta }}$ was set as the ratio between the number of differences between salsa-depleted and control emitted values that 
are greater than zero and the total number of differences, reflecting the probability of $\mathrm{PIR}_{\text {salsa RNAi }}$ being greater than $\mathrm{PIR}_{\text {control }}$ $\left(P_{\text {diff }}\right)$.

Differentially retained introns were considered as those with $P_{\text {diff }} \geq 0.9$. From these, introns that were more retained upon salsa depletion than in controls $\left(\Delta P \mid R_{\text {beta }}>0.1\right)$ were classified as Affected, while those showing decreased retention upon salsa depletion $\left(\Delta \mathrm{PIR} \mathrm{R}_{\text {beta }}<-0.1\right)$ were classified as Less Retained. Irrespectively of the significance of PIR differences, Affected introns showing very low inclusion levels in Control samples (mean PIR $<0.05$ ) were classified into a separate group, Affected low PIR. Included introns were set as those showing consistently high inclusion, i.e. with a PIR $\geq 0.75$ for all samples and an absolute $\Delta \mathrm{PIR}_{\text {beta }}<0.02$, while Skipped introns were classified as those always found spliced out, having $P I R=0$ for all samples. Finally, Control introns were classified as those showing $\mathrm{PIR}_{\text {salsa RNAi }}$ and PIR control between 0.05 and 0.9 (alternatively retained introns) but their retention does not seem to be affected by salsa depletion (absolute $\Delta \mathrm{PIR}_{\text {beta }}<0.02$ ).

MATT (Gohr and Irimia 2019) was used to retrieve intronic features, such as intron, upstream or downstream exon length, splice site strength (Yeo and Burge 2004) and GC content across groups using function get_ifeatures. Ensembl Biomart (Kinsella et al. 2011) was used to extract transcription start sites per transcript to calculate distance between these and the intron start $\left(5^{\prime} \mathrm{ss}\right)$. Differential alternative splicing analysis considering all event types annotated in vast-tools (Supplemental Fig. S2) was performed using the same filtering criteria as described above for intron retention.

\section{Differential gene expression analysis}

Gene expression was quantified with vast-tools, that aligns RNAseq reads against a reference transcriptome. Differential gene expression analysis was performed with the limma $R$ package (Ritchie et al. 2015). The magnitude of difference in expression was measured in $\log _{2}$ fold-change between control and salsa RNAi. Six genes were considered to be significantly differentially expressed (those with an associated positive empirical Bayes statistic giving the log-odds ratio of the gene being differentially expressed): CG4570 and Arc1 down-regulated and Drat, Cyp4p2, sev and Ilp6 up-regulated in salsa-depleted samples.

\section{DATA DEPOSITION}

All data generated or analyzed during this study are included in this published article (and its Supplemental Information Files). The RNA-seq data have been deposited in the Sequence Read Archive under accession number PRJNA655826.

\section{SUPPLEMENTAL MATERIAL}

Supplemental material is available for this article.

\section{ACKNOWLEDGMENTS}

We thank Julian König (IMB Mainz) for scientific discussions. We also thank Cláudia Florindo for assistance in fluorescence microscopy, the TRiP collection at Harvard Medical School (NIH/NIGMS
R01-GM084947) for providing several of the transgenic RNAi fly stocks used in this study, and Manuel Irimia (CRG Barcelona) for advance access to the Drosophila VAST-DB annotation. The Microscopy Unit was partially supported by Portuguese national funding (FCT: PPBI-POCI-01-0145-FEDER-022122). This work was developed with the support of the research infrastructure Congento (project LISBOA-01-0145-FEDER-022170). R.G.M. is supported by Portuguese national funding through Fundação para a Ciência e a Tecnologia (FCT grant refs. PTDC/BEX-BID/ 0395/2014, PTDC/BIA-BID/28441/2017, and UID/BIM/04773/ 2013 CBMR 1334). Nuno L. Barbosa-Morais is supported by European Molecular Biology Organization (EMBO) Installation Grant (3057), Investigador FCT Starting Grant (IF/00595/2014), UID/BIM/50005/2019, the project funded by Fundação para a Ciência e a Tecnologia (FCT)/Ministério da Ciência, Tecnologia e Ensino Superior (MCTES) through Fundos do Orçamento de Estado and iMM Lisboa start-up funds. O.S.R. and B.M. were supported by Portuguese national funding through Fundação para a Ciência e a Tecnologia, respectively, PD/BD/52428/2013 and $\mathrm{PD} / \mathrm{BD} / 128342 / 2017$, within the scope of the ProRegeM PhD program (ref. PD/00117/2012, CRM:0027030). O.S.R. was also supported by a Federation of European Biochemical societies (FEBS) short-term fellowship. M.A.-F. is supported by Fundação para a Ciência e Tecnologia (FCT) PhD fellowship (PD/BD/ 128283/2017) and Fundação AstraZeneca. R.D.S. is supported by Portuguese national funding through Fundação para a Ciência e a Tecnologia, ref. DL 57/2016/CP1361/CT0019. The funding bodies had no role in the design of this study, collection, analysis, and interpretation of data, and manuscript writing.

Author contributions: O.S.R.: investigation, writing (review and editing); R.D.S.: investigation; M.A-F: investigation, writing (review and editing); R.M.: investigation; B.M.: investigation; M.N.T.: investigation; P.P.: investigation, writing (review and editing); R.P.A.: conceptualization, writing (review and editing); J-Y.R.: conceptualization, writing (review and editing); N.L.B-M.: conceptualization, writing (review and editing); R.G.M.: conceptualization, writing (original draft, review, and editing).

Received August 12, 2020; accepted September 7, 2020.

\section{REFERENCES}

Abdu U, Brodsky M, Schupbach T. 2002. Activation of a meiotic checkpoint during Drosophila oogenesis regulates the translation of Gurken through Chk2/Mnk. Curr Biol 12: 1645-1651. doi:10 .1016/S0960-9822(02)01165-X

Akay A, Di Domenico T, Suen KM, Nabih A, Parada GE, Larance M, Medhi R, Berkyurek AC, Zhang X, Wedeles CJ, et al. 2017. The helicase aquarius/EMB-4 is required to overcome intronic barriers to allow nuclear RNAi pathways to heritably silence transcription. Dev Cell 42: 241-255.e246. doi:10.1016/j.devcel.2017.07.002

Ashe MP, Pearson LH, Proudfoot NJ. 1997. The HIV-1 5' LTR poly(A) site is inactivated by $U 1$ snRNP interaction with the downstream major splice donor site. EMBO J 16: 5752-5763. doi:10.1093/ emboj/16.18.5752

Bentley DL. 2014. Coupling mRNA processing with transcription in time and space. Nat Rev Genet 15: 163-175. doi:10.1038/ nrg3662

Brand AH, Perrimon N. 1993. Targeted gene expression as a means of altering cell fates and generating dominant phenotypes. Development 118: 401-415. 
Braunschweig U, Barbosa-Morais NL, Pan Q, Nachman EN, Alipanahi B, Gonatopoulos-Pournatzis T, Frey B, Irimia M, Blencowe BJ. 2014. Widespread intron retention in mammals functionally tunes transcriptomes. Genome Res 24: 1774-1786. doi:10.1101/gr.177790.114

Caceres L, Nilson LA. 2005. Production of gurken in the nurse cells is sufficient for axis determination in the Drosophila oocyte. Development 132: 2345-2353. doi:10.1242/dev.01820

Chanarat S, Strasser K. 2013. Splicing and beyond: the many faces of the Prp19 complex. Biochim Biophys Acta 1833: 2126-2134. doi:10.1016/j.bbamcr.2013.05.023

Damgaard CK, Kahns S, Lykke-Andersen S, Nielsen AL, Jensen TH, Kjems J. 2008. A $5^{\prime}$ splice site enhances the recruitment of basal transcription initiation factors in vivo. Mol Cell 29: 271-278. doi:10.1016/j.molcel.2007.11.035

David CJ, Boyne AR, Millhouse SR, Manley JL. 2011. The RNA polymerase II C-terminal domain promotes splicing activation through recruitment of a U2AF65-Prp19 complex. Genes Dev 25: 972-983. doi:10.1101/gad.2038011

Davidson A, Parton RM, Rabouille C, Weil TT, Davis I. 2016. Localized translation of gurken/TGF- $\alpha$ mRNA during axis specification is controlled by access to Orb/CPEB on processing bodies. Cell Rep 14: 2451-2462. doi:10.1016/j.celrep.2016.02.038

De I, Bessonov $S$, Hofele $R$, dos Santos K, Will CL, Urlaub H, Luhrmann R, Pena V. 2015. The RNA helicase Aquarius exhibits structural adaptations mediating its recruitment to spliceosomes. Nat Struct Mol Biol 22: 138-144. doi:10.1038/nsmb.2951

Dej KJ, Spradling AC. 1999. The endocycle controls nurse cell polytene chromosome structure during Drosophila oogenesis. Development 126: 293-303.

Delanoue R, Herpers B, Soetaert J, Davis I, Rabouille C. 2007. Drosophila Squid/hnRNP helps Dynein switch from a gurken mRNA transport motor to an ultrastructural static anchor in sponge bodies. Dev Cell 13: 523-538. doi:10.1016/j.devcel.2007.08.022

de Las Heras JM, Martinho RG, Lehmann R, Casanova J. 2009. A functional antagonism between the pgc germline repressor and torso in the development of somatic cells. EMBO Rep 10: 1059-1065. doi:10.1038/embor.2009.128

Ferreira T, Prudencio P, Martinho RG. 2014. Drosophila protein kinase $\mathrm{N}(\mathrm{Pkn})$ is a negative regulator of actin-myosin activity during oogenesis. Dev Biol 394: 277-291. doi:10.1016/j.ydbio.2014.08.008

Fox-Walsh KL, Dou Y, Lam BJ, Hung SP, Baldi PF, Hertel KJ. 2005. The architecture of pre-mRNAs affects mechanisms of splice-site pairing. Proc Natl Acad Sci 102: 16176-16181. doi:10.1073/pnas .0508489102

Ghabrial A, Schupbach T. 1999. Activation of a meiotic checkpoint regulates translation of Gurken during Drosophila oogenesis. Nat Cell Biol 1: 354-357. doi:10.1038/14046

Ghosh S, Marchand V, Gaspar I, Ephrussi A. 2012. Control of RNP motility and localization by a splicing-dependent structure in oskar mRNA. Nat Struct Mol Biol 19: 441-449. doi:10.1038/nsmb.2257

Gohr A, Irimia M. 2019. Matt: Unix tools for alternative splicing analysis. Bioinformatics 35: 130-132. doi:10.1093/bioinformatics/ bty606

Gonzalez-Reyes A, St Johnston D. 1994. Role of oocyte position in establishment of anterior-posterior polarity in Drosophila. Science 266: 639-642. doi:10.1126/science.7939717

Gonzalez-Reyes A, Elliott H, St Johnston D. 1995. Polarization of both major body axes in Drosophila by gurken-torpedo signalling. Nature 375: 654-658. doi:10.1038/375654a0

Goodrich JS, Clouse KN, Schupbach T. 2004. Hrb27C, Sqd and Otu cooperatively regulate gurken RNA localization and mediate nurse cell chromosome dispersion in Drosophila oogenesis. Development 131: 1949-1958. doi:10.1242/dev.01078
Gornemann J, Kotovic KM, Hujer K, Neugebauer KM. 2005. Cotranscriptional spliceosome assembly occurs in a stepwise fashion and requires the cap binding complex. Mol Cell 19: 53-63. doi:10.1016/j.molcel.2005.05.007

Graveley BR, Brooks AN, Carlson JW, Duff MO, Landolin JM, Yang L, Artieri CG, van Baren MJ, Boley N, Booth BW, et al. 2011. The developmental transcriptome of Drosophila melanogaster. Nature 471: 473-479. doi:10.1038/nature09715

Guilgur LG, Prudencio P, Sobral D, Liszekova D, Rosa A, Martinho RG. 2014. Requirement for highly efficient pre-mRNA splicing during Drosophila early embryonic development. Elife 3: e02181. doi:10.7554/eLife.02181

Gunderson SI, Polycarpou-Schwarz M, Mattaj IW. 1998. U1 snRNP inhibits pre-mRNA polyadenylation through a direct interaction between U1 70K and poly(A) polymerase. Mol Cell 1: 255-264. doi:10.1016/S1097-2765(00)80026-X

Guo J, Garrett M, Micklem G, Brogna S. 2011. Poly(A) signals located near the $5^{\prime}$ end of genes are silenced by a general mechanism that prevents premature 3'-end processing. Mol Cell Biol 31: 639-651. doi:10.1128/MCB.00919-10

Hachet O, Ephrussi A. 2004. Splicing of oskar RNA in the nucleus is coupled to its cytoplasmic localization. Nature 428: 959-963. doi:10.1038/nature02521

Haselbach D, Komarov I, Agafonov DE, Hartmuth K, Graf B, Dybkov O, Urlaub H, Kastner B, Luhrmann R, Stark H. 2018. Structure and conformational dynamics of the human spliceosomal B ${ }^{\text {act }}$ complex. Cell 172: 454-464. doi:10.1016/j.cell.2018.01 .010

Herold N, Will CL, Wolf E, Kastner B, Urlaub H, Luhrmann R. 2009. Conservation of the protein composition and electron microscopy structure of Drosophila melanogaster and human spliceosomal complexes. Mol Cell Biol 29: 281-301. doi:10.1128/MCB.0141508

Hirose T, Ideue T, Nagai M, Hagiwara M, Shu MD, Steitz JA. 2006. A spliceosomal intron binding protein, IBP160, links position-dependent assembly of intron-encoded box C/D snoRNP to pre-mRNA splicing. Mol Cell 23: 673-684. doi:10.1016/j.molcel.2006.07.011

Hogg R, McGrail JC, O'Keefe RT. 2010. The function of the NineTeen Complex (NTC) in regulating spliceosome conformations and fidelity during pre-mRNA splicing. Biochem Soc Trans 38: 11101115. doi:10.1042/BST0381110

Hoskins AA, Friedman LJ, Gallagher SS, Crawford DJ, Anderson EG, Wombacher R, Ramirez N, Cornish VW, Gelles J, Moore MJ. 2011. Ordered and dynamic assembly of single spliceosomes. Science 331: 1289-1295. doi:10.1126/science.1198830

Huynh JR, St Johnston D. 2004. The origin of asymmetry: early polarisation of the Drosophila germline cyst and oocyte. Curr Biol 14: R438-R449. doi:10.1016/j.cub.2004.05.040

Ideue T, Sasaki YT, Hagiwara M, Hirose T. 2007. Introns play an essential role in splicing-dependent formation of the exon junction complex. Genes Dev 21: 1993-1998. doi:10.1101/gad.1557907

Irimia M, Weatheritt RJ, Ellis JD, Parikshak NN, GonatopoulosPournatzis T, Babor M, Quesnel-Vallieres M, Tapial J, Raj B, O'Hanlon D, et al. 2014. A highly conserved program of neuronal microexons is misregulated in autistic brains. Cell 159: 15111523. doi:10.1016/j.cell.2014.11.035

Izaurralde E, Lewis J, McGuigan C, Jankowska M, Darzynkiewicz E, Mattaj IW. 1994. A nuclear cap binding protein complex involved in pre-mRNA splicing. Cell 78: 657-668. doi:10.1016/0092-8674 (94)90530-4

Khodor YL, Rodriguez J, Abruzzi KC, Tang CH, Marr MT II, Rosbash M. 2011. Nascent-seq indicates widespread cotranscriptional premRNA splicing in Drosophila. Genes Dev 25: 2502-2512. doi:10 $.1101 /$ gad.178962.111 
Kinsella RJ, Kahari A, Haider S, Zamora J, Proctor G, Spudich G, Almeida-King J, Staines D, Derwent P, Kerhornou A, et al. 2011. Ensembl BioMarts: a hub for data retrieval across taxonomic space. Database (Oxford) 2011: bar030. doi:10.1093/database/ bar030

Klattenhoff C, Bratu DP, McGinnis-Schultz N, Koppetsch BS, Cook HA, Theurkauf WE. 2007. Drosophila rasiRNA pathway mutations disrupt embryonic axis specification through activation of an ATR/Chk2 DNA damage response. Dev Cell 12: 45-55. doi:10.1016/j.devcel.2006.12.001

Kuraoka I, Ito S, Wada T, Hayashida M, Lee L, Saijo M, Nakatsu Y, Matsumoto $M$, Matsunaga $T$, Handa $H$, et al. 2008. Isolation of XAB2 complex involved in pre-mRNA splicing, transcription, and transcription-coupled repair. J Biol Chem 283: 940-950. doi:10 .1074/jbc.M706647200

Lan L, Lin S, Zhang S, Cohen RS. 2010. Evidence for a transport-trap mode of Drosophila melanogaster gurken mRNA localization. PLOS ONE 5: e15448. doi:10.1371/journal.pone.0015448

Lepennetier G, Catania F. 2016. mRNA-associated processes and their influence on exon-intron structure in Drosophila melanogaster. G3 (Bethesda) 6: 1617-1626. doi:10.1534/g3.116 .029231

Lewis JD, Izaurralde E, Jarmolowski A, McGuigan C, Mattaj IW. 1996. A nuclear cap-binding complex facilitates association of U1 snRNP with the cap-proximal 5' splice site. Genes Dev 10: 1683-1698. doi:10.1101/gad.10.13.1683

Lin K, Zhang DY. 2005. The excess of $5^{\prime}$ introns in eukaryotic genomes. Nucleic Acids Res 33: 6522-6527. doi:10.1093/nar/gki970

MacDougall N, Clark A, MacDougall E, Davis I. 2003. Drosophila gurken (TGF $\alpha$ ) mRNA localizes as particles that move within the oocyte in two dynein-dependent steps. Dev Cell 4: 307-319. doi:10.1016/S1534-5807(03)00058-3

Mahajan K. 2016. hPso4/hPrp19: a critical component of DNA repair and DNA damage checkpoint complexes. Oncogene 35: 22792286. doi:10.1038/onc.2015.321

Marechal A, Li JM, Ji XY, Wu CS, Yazinski SA, Nguyen HD, Liu S, Jimenez AE, Jin J, Zou L. 2014. PRP19 transforms into a sensor of RPA-ssDNA after DNA damage and drives ATR activation via a ubiquitin-mediated circuitry. Mol Cell 53: 235-246. doi:10 .1016/j.molcel.2013.11.002

Martinho RG, Guilgur LG, Prudencio P. 2015. How gene expression in fast-proliferating cells keeps pace. Bioessays 37: 514-524. doi:10 .1002/bies.201400195

Morisato D, Anderson KV. 1994. The spatzle gene encodes a component of the extracellular signaling pathway establishing the dorsalventral pattern of the Drosophila embryo. Cell 76: 677-688. doi:10 .1016/0092-8674(94)90507-X

Navarro-Costa P, McCarthy A, Prudencio P, Greer C, Guilgur LG, Becker JD, Secombe J, Rangan P, Martinho RG. 2016. Early programming of the oocyte epigenome temporally controls late prophase I transcription and chromatin remodelling. Nat Commun 7: 12331. doi:10.1038/ncomms12331

Neuman-Silberberg FS, Schupbach T. 1993. The Drosophila dorsoventral patterning gene gurken produces a dorsally localized RNA and encodes a TGF $\alpha$-like protein. Cell 75: 165-174. doi:10 .1016/S0092-8674(05)80093-5

Neuman-Silberberg FS, Schupbach T. 1994. Dorsoventral axis formation in Drosophila depends on the correct dosage of the gene gurken. Development 120: 2457-2463.

Ni JQ, Zhou R, Czech B, Liu LP, Holderbaum L, Yang-Zhou D, Shim HS, Tao R, Handler D, Karpowicz P, et al. 2011. A genome-scale shRNA resource for transgenic RNAi in Drosophila. Nat Methods 8: 405407. doi:10.1038/nmeth.1592
Nolan T, Hands RE, Bustin SA. 2006. Quantification of mRNA using real-time RT-PCR. Nat Protoc 1: 1559-1582. doi:10.1038/nprot 2006.236

Pabis M, Neufeld N, Steiner MC, Bojic T, Shav-Tal Y, Neugebauer KM. 2013. The nuclear cap-binding complex interacts with the U4/U6. U5 tri-snRNP and promotes spliceosome assembly in mammalian cells. RNA 19: 1054-1063. doi:10.1261/rna.037069.112

Pai AA, Henriques T, McCue K, Burkholder A, Adelman K, Burge CB. 2017. The kinetics of pre-mRNA splicing in the Drosophila genome and the influence of gene architecture. Elife 6: e32537. doi:10.7554/eLife.32537

Papasaikas P, Valcarcel J. 2016. The spliceosome: the ultimate RNA chaperone and sculptor. Trends Biochem Sci 41: 33-45. doi:10 .1016/j.tibs.2015.11.003

Popp MW, Maquat LE. 2013. Organizing principles of mammalian nonsense-mediated mRNA decay. Annu Rev Genet 47: 139165. doi:10.1146/annurev-genet-111212-133424

Prudencio P, Guilgur LG, Sobral J, Becker JD, Martinho RG, NavarroCosta P. 2018. The Trithorax group protein dMLL3/4 instructs the assembly of the zygotic genome at fertilization. EMBO Rep 19: e45728. doi:10.15252/embr.201845728

Qiu J, Cheng F, Pintel D. 2007. Distance-dependent processing of adeno-associated virus type 5 RNA is controlled by $5^{\prime}$ exon definition. J Virol 81: 7974-7984. doi:10.1128/JVI.00714-07

Queenan AM, Barcelo G, Van Buskirk C, Schupbach T. 1999. The transmembrane region of Gurken is not required for biological activity, but is necessary for transport to the oocyte membrane in Drosophila. Mech Dev 89: 35-42. doi:10.1016/S0925-4773(99) 00196-3

Ritchie ME, Phipson B, Wu D, Hu Y, Law CW, Shi W, Smyth GK. 2015. limma powers differential expression analyses for RNA-sequencing and microarray studies. Nucleic Acids Res 43: e47. doi:10 $.1093 /$ nar/gkv007

Rorth P. 1998. Gal4 in the Drosophila female germline. Mech Dev 78: 113-118. doi:10.1016/S0925-4773(98)00157-9

Roth S, Neuman-Silberberg FS, Barcelo G, Schupbach T. 1995. cornichon and the EGF receptor signaling process are necessary for both anterior-posterior and dorsal-ventral pattern formation in Drosophila. Cell 81: 967-978. doi:10.1016/0092-8674(95) 90016-0

Sakurai A, Fujimori S, Kochiwa H, Kitamura-Abe S, Washio T, Saito R, Carninci P, Hayashizaki Y, Tomita M. 2002. On biased distribution of introns in various eukaryotes. Gene 300: 89-95. doi:10.1016/ S0378-1119(02)01035-1

Saunders C, Cohen RS. 1999. The role of oocyte transcription, the $5^{\prime}$ UTR, and translation repression and derepression in Drosophila gurken mRNA and protein localization. Mol Cell 3: 43-54. doi:10 .1016/S1097-2765(00)80173-2

Schmittgen TD, Livak KJ. 2008. Analyzing real-time PCR data by the comparative $C_{\mathrm{T}}$ method. Nat Protoc 3: 1101-1108. doi:10.1038/ nprot.2008.73

Schneider DS, Jin Y, Morisato D, Anderson KV. 1994. A processed form of the Spatzle protein defines dorsal-ventral polarity in the Drosophila embryo. Development 120: 1243-1250.

Schupbach T. 1987. Germ line and soma cooperate during oogenesis to establish the dorsoventral pattern of egg shell and embryo in Drosophila melanogaster. Cell 49: 699-707. doi:10.1016/00928674(87)90546-0

Sterner DA, Carlo T, Berget SM. 1996. Architectural limits on split genes. Proc Natl Acad Sci 93: 15081-15085. doi:10.1073/pnas 93.26.15081

Styhler S, Nakamura A, Swan A, Suter B, Lasko P. 1998. vasa is required for GURKEN accumulation in the oocyte, and is involved in oocyte differentiation and germline cyst development. Development 125: 1569-1578. 


\section{Rathore et al.}

Tapial J, Ha KCH, Sterne-Weiler T, Gohr A, Braunschweig U, Hermoso-Pulido A, Quesnel-Vallieres M, Permanyer J, Sodaei R, Marquez $Y$, et al. 2017. An atlas of alternative splicing profiles and functional associations reveals new regulatory programs and genes that simultaneously express multiple major isoforms. Genome Res 27: 1759-1768. doi:10.1101/gr.220962.117

Thio GL, Ray RP, Barcelo G, Schupbach T. 2000. Localization of gurken RNA in Drosophila oogenesis requires elements in the $5^{\prime}$ and $3^{\prime}$ regions of the transcript. Dev Biol 221: 435-446. doi:10.1006/dbio .2000 .9690

Torres-Mendez A, Bonnal S, Marquez Y, Roth J, Iglesias $M$, Permanyer J, Almudi I, O'Hanlon D, Guitart T, Soller M, et al. 2019. A novel protein domain in an ancestral splicing factor drove the evolution of neural microexons. Nat Ecol Evol 3: 691-701. doi:10.1038/s41559-019-0813-6

Van Buskirk C, Schupbach T. 2002. Half pint regulates alternative splice site selection in Drosophila. Dev Cell 2: 343-353. doi:10 .1016/S1534-5807(02)00128-4

Van De Bor V, Hartswood E, Jones C, Finnegan D, Davis I. 2005. gurken and the I factor retrotransposon RNAs share common localization signals and machinery. Dev Cell 9: 51-62. doi:10.1016/j .devcel.2005.04.012
Vandesompele J, De Preter K, Pattyn F, Poppe B, Van Roy N, De Paepe A, Speleman F. 2002. Accurate normalization of real-time quantitative RT-PCR data by geometric averaging of multiple internal control genes. Genome Biol 3: RESEARCH0034. doi:10 .1186/gb-2002-3-7-research0034

Van Doren M, Williamson AL, Lehmann R. 1998. Regulation of zygotic gene expression in Drosophila primordial germ cells. Curr Biol 8: 243-246. doi:10.1016/S0960-9822(98)70091-0

Vert JP, Foveau N, Lajaunie C, Vandenbrouck Y. 2006. An accurate and interpretable model for siRNA efficacy prediction. BMC Bioinformatics 7: 520. doi:10.1186/1471-2105-7-520

Wan L, Huang J. 2014. The PSO4 protein complex associates with replication protein $A$ (RPA) and modulates the activation of ataxia telangiectasia-mutated and Rad3-related (ATR). J Biol Chem 289: 6619-6626. doi:10.1074/jbc.M113.543439

Yeo G, Burge CB. 2004. Maximum entropy modeling of short sequence motifs with applications to RNA splicing signals. J Comput Biol 11: 377-394. doi:10.1089/1066527041410418

Zhao T, Graham OS, Raposo A, St Johnston D. 2012. Growing microtubules push the oocyte nucleus to polarize the Drosophila dorsalventral axis. Science 336: 999-1003. doi:10.1126/science .1219147 

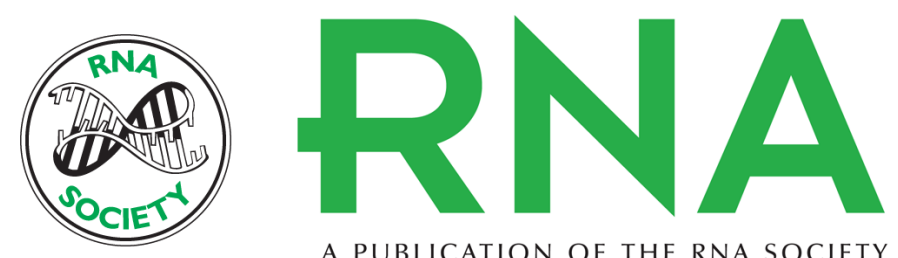

A PUBLICATION OF THE RNA SOCIETY

\section{NineTeen Complex-subunit Salsa is required for efficient splicing of a subset of introns and dorsal-ventral patterning}

Om Singh Rathore, Rui D. Silva, Mariana Ascensão-Ferreira, et al.

RNA 2020 26: 1935-1956 originally published online September 22, 2020

Access the most recent version at doi:10.1261/rna.077446.120

\section{Supplemental http://rnajournal.cshlp.org/content/suppl/2020/09/22/rna.077446.120.DC1 \\ Material}

References This article cites 84 articles, 27 of which can be accessed free at: http://rnajournal.cshlp.org/content/26/12/1935.full.html\#ref-list-1

Creative This article is distributed exclusively by the RNA Society for the first 12 months after the Commons

License full-issue publication date (see http://rnajournal.cshlp.org/site/misc/terms.xhtml). After 12 months, it is available under a Creative Commons License (Attribution-NonCommercial 4.0 International), as described at http://creativecommons.org/licenses/by-nc/4.0/.

Email Alerting Receive free email alerts when new articles cite this article - sign up in the box at the Service top right corner of the article or click here. 